\title{
Headache in people with epilepsy
}

Prisca R. Bauer ${ }^{1, \dagger}$, Else A. Tolner ${ }^{2,3}$, Mark R Keezer ${ }^{4,5,6}$, Michel D Ferrari ${ }^{2}$ and Josemir W Sander ${ }^{6,7,8}$

1. Department of Psychosomatic Medicine and Psychotherapy, University Medical Center Freiburg, Freiburg, Germany

2. Department of Neurology, Leiden University Medical Centre, Leiden, Netherlands

3. Department of Human Genetics, Leiden University Medical Centre, Leiden, Netherlands

4. Research Centre of the Centre Hospitalier de l'Université de Montréal (CRCHUM), Montreal, Canada

5. School of Public Health, Université de Montréal, Montreal, Canada

6. Stichting Epilepsie Instellingen Nederland (SEIN), Heemstede, Netherlands

7. NIHR University College London Hospitals Biomedical Research Centre UCL Queen Square Institute of Neurology, London, United Kingdom

8. Chalfont Centre for Epilepsy, Chalfont St Peter, United Kingdom

†email: Prisca.bauer@uniklink-freiburg.de

\begin{abstract}
Epidemiological estimations indicate that individuals with epilepsy are more likely to experience headaches, including migraine than individuals without epilepsy. Headaches can be temporally unrelated to seizures, or can occur before, during or after an episode; seizures and migraine attacks are mostly not temporally linked. The pathophysiological links between headaches (including migraine) and epilepsy are complex and have not yet been fully elucidated. Correct diagnoses and appropriate treatment of headaches in individuals with epilepsy is essential, as headaches can contribute substantially to disease burden. Here, we review the insights that have been made into the associations between headache and epilepsy over the last 5 years, including information on the
\end{abstract}


pathophysiological mechanisms and genetic variants that link the two disorders. We also discuss the current best practice for the management of headaches co-occurring with epilepsy and highlight future challenges for this area of research.

\section{[H1] Introduction}

The hallmark of epilepsy is an enduring predisposition to seizures accompanied by neurobiological, cognitive and psychological comorbidities ${ }^{1}$. Epileptic seizures are defined as the disruption of normal neuronal functioning owing to excessive or synchronous neuronal activity, leading to an epileptic event that is discernible by the person and/or by an observer ${ }^{1}$. An analysis for the Global Burden of Disease Study 2016 estimated that $>50$ million people worldwide had active epilepsy, that is, they had continuing seizures or were receiving epilepsy treatment ${ }^{2}$. The origin and cause of seizures can vary. The International League Against Epilepsy (ILAE) scheme ${ }^{3}$ classifies seizures as either "focal", meaning that seizures originate at a specific location in one hemisphere; "generalised", denoting seizures that engage bilaterally distributed networks; or "unknown", for seizures with an undefined origin. The ILAE classifies epilepsy as either "focal", "generalised", "focal and generalised", or "unknown", depending on the type of seizures that occur ${ }^{3}$. The same scheme also classifies epilepsy according to aetiology, including "structural" (for example, associated with a brain tumour or gliosis), "genetic", "metabolic" (for example, associated with mitochondrial disease), "infectious", "immune" or "unknown"3. The category "unknown" includes genetic, metabolic and structural causes that have not yet been identified.

Headaches are among the commonest disorders globally — the Global burden of Disease Study 2017 estimated that there were $>3$ billion individuals with headache across 195 countries and territories ${ }^{4}$. The International Classification of Headache Disorders 3 (ICHD-3) ${ }^{5}$ distinguishes between primary headaches — including migraine, tension-type headache (TTH) and trigeminal autonomic cephalalgias — and secondary headaches, which are attributable to other disorders or substances. TTH, which affects $>2$ billion people globally ${ }^{4}$, is a poorly defined featureless headache that lacks the characteristic features of other primary headaches and is usually bilateral and pressing (non-pulsating) ${ }^{5}$. TTH can last for 30 minutes to seven days, is not usually aggravated by routine physical activity and is not accompanied by nausea, vomiting or photo-phobia or phonophobia ${ }^{5}$. 
Global migraine prevalence is $\sim 1.3$ billion and the disorder is $3-4$ times more common in women than men ${ }^{4}$. Migraine is a heterogeneous brain disorder, typically characterised by recurrent attacks of mostly severe unilateral pulsating headache lasting 4-72 hours, accompanied by nausea, vomiting and/or hypersensitivity to sensory stimuli, and a range of other sensory and cognitive symptoms ${ }^{5}$. In about $30 \%$ of individuals with migraine, the pain is preceded - and in rare cases accompanied or followed by — a migraine aura, consisting of transient focal neurological symptoms. Symptoms of migraine aura are usually visual but may involve tactile, motor and/or speech disturbances ${ }^{6}$. Some individuals have auras without headache ${ }^{7}$

Here, we review the link between epilepsy and headaches, starting with the epidemiology of the two disorders. We then discuss the diagnosis and classification of headaches in epilepsy and provide an overview of the current understanding of the underlying pathophysiological mechanisms. Last, we discuss the clinical management of co-existing headaches and epilepsy. We focus on evidence published between 2015 and 2020 to provide a view of recent progress in the field, and we also provide a timeline of key publications from before 2015 (Fig. 1.).

\section{[H1] Epidemiological evidence}

Headaches, especially migraine, and epilepsy frequently co-exist in the same individuals. A meta-analysis of population-based studies of migraine in people with epilepsy published between 1996 and 2012 indicated that lifetime migraine prevalence was $52 \%$ greater in people with epilepsy than in people without epilepsy ${ }^{8}$. The lifetime epilepsy prevalence was also $79 \%$ greater in people with migraine than in people without migraine. A more recent meta-analysis (including studies published between 2004 and 2019) estimated a 49\% prevalence of unspecified headache among people with epilepsy ${ }^{9}$. Additional evidence has confirmed the findings of these meta-analyses regarding the co-existence of epilepsy and headache (Table 1$)^{10-19}$. In these studies, $\leq 79 \%$ of individuals with epilepsy reported experiencing headaches. The most common headache types in individuals with epilepsy were migraine (reported by $\leq 25 \%$ of participants) and TTH (reported by $\leq 40 \%$ of participants) $)^{10,13,14,16,18}$. Women with epilepsy tended to report migraine more often than men with epilepsy ${ }^{11,12,16,18,20}$. No clear relationship between headache type and epileptic focus location, seizure type, seizure frequency, or use of antiseizure medication was identified in these recent studies ${ }^{13,16}$. One older study reported that peri-ictal headaches were ipsilateral to the epileptic focus in temporal epilepsy, but not in extra-temporal epilepsy ${ }^{22}$. Some researchers 
have suggested that the association between headache and epilepsy is stronger in individuals with genetic forms of epilepsy than those with non-genetic forms, and stronger in children than in adults ${ }^{23}$, One study reported a negative correlation between headache frequency and age of epilepsy onset ${ }^{11}$ comparative meta-analytic evidence to support this finding is lacking.

\section{[H2] Limitations of epidemiological studies}

Epidemiological studies have offered important insights into the relationship between epilepsy and headache but can be subject to biases, which might influence findings. First, the case-ascertainment method used often influences study findings, for example, studies that use self-report questionnaires tend to show a stronger association between headache and epilepsy than those that rely upon a physician's assessment ${ }^{8}$. This disparity might be caused by the fact that few validated instruments exist for self-diagnosis of epilepsy or headaches ${ }^{24}$ studies often use their own, unvalidated instruments ${ }^{8}$, the accuracy of which is unknown. How questions are formulated can influence the responses; for example, the results of one study suggested that people with epilepsy were three times more likely to report headaches preceding seizures when asked closed-ended questions than when asked open-ended questions ${ }^{25}$.

Second is the effect of recall bias on findings ${ }^{26}$. Evidence indicates that, compared with healthy individuals, individuals with a pre-existing condition are more likely to report additional symptoms ${ }^{26}$. This observation might explain why individuals with epilepsy report migraine more often than individuals without epilepsy ${ }^{8}$. Conversely, seizures can be associated with amnesia, which would make it difficult for the individual to recall what happened just prior, during or after the seizure, thus preventing the reporting of comorbidities such as headache ${ }^{27}$. Additionally, seizures are often conspicuous events and could overshadow less apparent complaints like headache, especially in children. Consequently, individuals with epilepsy might perceive headaches as "mundane" and thus not report them unless directly asked.

Third, physicians might not be aware that headaches are common in individuals with epilepsy ${ }^{27-29}$, which could introduce misclassification bias $^{26}$. This type of bias could occur when the health provider is more or less attentive to comorbidities contingent on whether the individual has a debilitating condition. A serious ailment might prompt physicians to look for other associated conditions. However, an individual might be so ill that "milder" symptoms or diseases are overlooked or seen as part of the significant condition. We hypothesize that this bias 
could explain why studies based on physician assessment show a lower association between epilepsy and headaches than studies based on self-assessment ${ }^{8}$.

Last, although studies that use insurance data or International Classification of Diseases codes have the advantage of physician-diagnosed data from large cohorts of individuals, the use of codes and insurance labels can be influenced by local policies. The choice of codes used might be influenced by financial or insurance-related factors, also resulting in biases. Despite these various sources of bias, epidemiological studies are essential in ascertaining the overlap between different conditions. Designing studies that are totally free of bias is impossible but bias can be reduced during the data collection phase and taken into account when interpreting results.

\section{[H2] A bidirectional relationship}

Whether epilepsy and headaches have a "bidirectional" association - meaning that the occurrence of one influences the onset of the other and vice versa - remains unknown. To date, most studies of the association between epilepsy and headaches have been cross-sectional, so do not allow for such assessments. To assert that a relationship between two conditions is bidirectional, a precise determination of condition B's onset in relation to condition A is required, and thus costly and labour-intensive longitudinal studies are needed. One such study evaluated the risk of developing subsequent epilepsy when first diagnosed with migraine and found that individuals with migraine and those who had migraine and sleep disorders, cognitive disorders, anxiety or depression were more likely to develop epilepsy than healthy individuals ${ }^{30}$. This cohort was followed-up for a mean period of 12 years, and the relative risk of developing epilepsy was found to be 2.3 times higher in men than in women ${ }^{31}$. Risk was increased by older age, low-income status and comorbidities, especially head trauma. For example, the risk of developing epilepsy was 4.6 times higher in men with migraine and a history of head trauma than in men with migraine and no history of head trauma ${ }^{31}$. These studies are longitudinal, but only assessed the risk of developing epilepsy in people with migraine and do not provide information on whether or not the relationship is truly bidirectional. Multi-centre prospective, long-term studies with clear diagnostic criteria will be vital to shed light on the complex relationship between epilepsy and headache and help identify individuals at risk of developing severe or chronic forms of either condition.

\section{[H1] Diagnosis and classification}

Headaches that co-occur with epilepsy can be classified according to their temporal relationship to seizures (Fig. 
2). Interictal headaches occur $>24$ hours before and $>72$ hours after epileptic seizures. Peri-ictal headaches, including migraine, occur shortly before, during or just after an epileptic seizure and can present a diagnostic challenge. The distinction between epilepsy and peri-ictal headaches is often apparent, the conditions can sometimes overlap either temporally or in terms of symptoms. These temporally classified types of headache (pre-ictal, post-ictal, ictal and interictal headache) can occur in the same individual (table 1).

Accurate classification of epilepsy and headache is important for initiating adequate, timely and appropriate treatment and requires a good description of the symptoms and their temporal relationships. The ILAE seizure classification scheme does not include a class of seizures with symptoms that overlap with headaches. However, the ICHD-3 includes several categories of seizure-related headaches ${ }^{5}$ (Box 1): migraine aura-triggered seizure (section 1.4.4), ictal epileptic headache (section 7.6.1) and post-ictal headache (section 7.6.2).

\section{[H2] Pre-ictal headaches}

Headaches that occur $<24$ hours before a seizure and last until seizure onset have been defined as pre-ictal ${ }^{11}$. According to the ICHD- $3^{5}$, the existence of pre-ictal headaches is controversial ${ }^{5}$, even though they have been reported in several studies ${ }^{32-35}$. The issue is that an EEG recording of the headache event is mandatory for the diagnosis of pre-ictal headache - for a headache to be pre-ictal, it must not be accompanied by ictal epileptic discharges on the EEG - and the studies cited above did not include an EEG recording of the event ${ }^{32-35}$. Headache concomitant with ictal epileptic discharges should be classified as ictal epileptic headache (see below). A classification of pre-ictal headache is not given in the ICHD-3 $3^{5}$, but the comments section calls for more studies to establish the existence, prevalence and features of this type of headache. The results of cohort studies suggest that possible pre-ictal headaches (without EEG confirmation) occur in $1-10 \%$ of people with epilepsy ${ }^{10,12-15,19,21}$ - (Table 1) the headache is migraine-like in $30-60 \%$ of these individuals and tension-type in $\sim 20 \%{ }^{10-15,17,19,21}$. In a video-EEG study, 25 of $831(6.3 \%)$ individuals with epilepsy reported pre-ictal headache without epileptic discharges on the $\mathrm{EEG}^{17}$. Five had "headache as a seizure aura", which should be classified as "ictal epileptic headache", see below ${ }^{17}$.

\section{[H2] Migraine-aura triggered seizures}


The term aura is used to describe subjective precursory symptoms of seizures and migraine headaches; however, it refers to different phenomena in the context of migraine or epilepsy. The ICHD- $3^{5}$ defines aura as "recurrent attacks, lasting (5-60) minutes, of unilateral fully reversible visual, sensory, motor or other central nervous system symptoms that usually develop gradually and are usually followed by headache and associated migraine symptoms." (Box 2). In contrast, a report by the ILAE Task Force on Classification and Terminology describes aura as "A subjective ictal phenomenon that, in a given individual, may precede an observable seizure; if alone, constitutes a sensory seizure." ${ }^{36}$ An epileptic aura is confirmed by epileptic discharges on EEG and is part of the seizure $^{36}$. Some epileptic auras do not have a visible EEG correlate as they can be very focal, occupying such a small cortical area that the spatial resolution of surface EEG is insufficient to detect them ${ }^{37}$.

In migraine, no consistent EEG abnormalities are observed during the aura and headache phase ${ }^{38,39}$. Studies have found either slow waves, attenuation of background activity amplitude or the presence of normal EEG patterns during migraine aura ${ }^{38,40}$. During attacks of hemiplegic migraine and migraine with disturbed consciousness, abnormal EEG patterns with unilateral or bilateral delta activity have been recorded ${ }^{40}$. The EEG has no diagnostic value in migraine (or headaches) ${ }^{38}$, but is mandatory for diagnosis of epilepsy, which also applies to individuals with epilepsy and comorbid headache ${ }^{41}$.

In rare cases, a migraine-like aura can occur immediately before a seizure ${ }^{5}$. The ICHD-3 refers to seizures that occur during or $<1$ hour after the end of a migraine with aura attack as "A seizure triggered by an attack of migraine with aura" ${ }^{\prime 5}$. These seizures are sometimes referred to as migralepsy ${ }^{5}$. Visual symptoms and hallucinations are hallmarks of migraine aura and occipital epilepsy, making it difficult to distinguish between the two conditions. In a meta-analysis published in 2019, the most common visual symptoms of migraine aura reported were foggy and/or blurred vision, zigzag or jagged lines, scotoma, phosphenes and flickering light ${ }^{42}$. (Table 2) The symptoms of occipital epilepsy are elementary and visual hallucinations or illusions; blindness; palinopsia and sensory hallucinations of ocular movements; ocular pain and oculomotor symptoms, including deviation of the eyes; and nystagmus and repetitive eyelid closure or fluttering ${ }^{43}$. The duration of symptoms is the most helpful feature for differentiating between migraine-related aura and occipital epilepsy ${ }^{44}$ : the median duration of migraine aura is $\sim 25$ minutes, whereas epileptic visual hallucinations last $<1$ minute ${ }^{45}$. The hallmark of migraine aura is a slowly progressive centrifugal or centripetal scotoma that expands over $10-60$ minutes ${ }^{5,42}$; 
a feature not described by people with occipital epilepsy ${ }^{43,45}$. In migraine, visual symptoms are almost always lateralised ${ }^{5}$. Similarly, event-associated nausea, vomiting, photophobia and phonophobia occur more often in migraine with aura than in occipital epilepsy ${ }^{45}$. Clinically, the simultaneous occurrence of positive and negative phenomena is more suggestive of a migraine aura than of epilepsy $y^{5,43,45}$.

The overlapping features of migraine aura and occipital seizures means that diagnosis requires a detailed description of the subjective symptoms, and pre-ictal and ictal EEG recordings. The absence of epileptiform abnormalities when the symptoms are present is the gold standard for ruling out an epileptic origin. The lack of epileptic EEG abnormalities during the migraine aura phase is essential for diagnosing migraine aura-triggered seizure. Experts doubt the existence of migraine aura-triggered seizures ${ }^{46-48}$ as pre-ictal and ictal EEG recordings often confirm an epileptic rather than a migraineous origin of the symptoms. For example, in one EEG study, 16 out of a cohort of 4,600 children diagnosed with epilepsy had an epileptic seizure $<1$ hour after a presumed migraine attack. These children had focal or generalized ictal EEG abnormalities during the migraine phase, indicating an epileptic origin of the migraine-like symptoms ${ }^{46}$. In a more recent study involving a large cohort of individuals with epilepsy, three participants $(<1 \%)$ reported epileptic seizures within an hour of an attack of migraine with aura. Two of these individuals were diagnosed with occipital epilepsy — the migraine-like aura was interpreted as an occipital seizure - and the third was diagnosed with epilepsy secondary to systematic lupus erythematosus $^{49}$. In a case report, two individuals presented with visual auras lasting 13-17 minutes, followed by a forceful turning of the head and, in one individual, a generalised tonic-clonic seizure ${ }^{48}$. EEG recordings showed a left occipital seizure in the first individual and a right parietal-occipital seizure in the other individual. We observed a similar presentation in one of our patients, who presented with headache accompanied by epileptic discharges on the EEG (Supplementary video 1). These individuals, in whom epileptic discharges accompany the visual symptoms and headaches on the EEG, should receive a diagnosis of ictal epileptic headache (see below), not migraine aura-triggered seizures, highlighting the challenges involved in diagnosing these conditions.

\section{[H2] Ictal epileptic headache}

A headache accompanied by epileptic abnormalities on the EEG is classified as an "ictal epileptic headache" by the ICHD- $3^{5}$. The headache should develop simultaneously with the seizure, and either be ipsilateral to the ictal discharge and/or show a substantial reduction in severity immediately after the seizure has terminated. Ictal 
epileptic headache can be accompanied or followed by other epileptic manifestations, such as motor, sensory or autonomic signs ${ }^{50}$. If 'pure' or 'isolated' ictal epileptic headache is the only manifestation of a seizure, it requires a differential diagnosis from other types of headache. In the ICHD-3 'hemicrania epileptica' signifies a rare variant of ictal epileptic headache, characterised by headache that is ipsilateral to ictal EEG paroxysms ${ }^{5}$. The precise definitions of the terms 'hemicrania epileptica' and 'ictal epileptic headache' have, however, been extensively debated ${ }^{27,29,51-53}$. Indeed, the ICHD-3 begins the definition of hemicrania epileptic with "if confirmed to exist", indicating the difficulties involved in confirming this diagnosis - EEG recordings are rarely performed in individuals with isolated headache. However, a video-EEG study did identify two instances of hemicrania epileptica $^{17}$

People with ictal epileptic headache can have interictal abnormalities on the $\mathrm{EEG}^{53}$. The diagnosis is confirmed by the presence of epileptiform patterns on the ictal EEG; however, as these abnormalities can occur with different types of lesional and non-lesional epilepsy, there is no unique EEG pattern linked to ictal epileptic headache ${ }^{27,53}$. Persistent ictal epileptic headache can occur in non-convulsive status epilepticus and in some individuals the headache only resolves after intravenous administration of anti-seizure medication ${ }^{27}$. Some researchers have suggested that an ability of anti-seizure medication to resolve the headache and the epileptic discharges on the EEG should be added as a diagnostic criterion for ictal epileptic headache ${ }^{51,54}$. Our view is that, owing to potential pharmacokinetic and pharmacodynamic differences between individuals, a response to treatment should not be part of a clinical definition.

EEG recordings have little diagnostic value in the majority of individuals with isolated headaches, including migraines, so are rarely performed in this group of people ${ }^{38}$. Therefore, ictal epileptic headache, although rare, is probably underdiagnosed. For example, one study reported that out of 831 people with epilepsy and peri-ictal headaches who underwent video-EEG monitoring, six had "headache as an aura of a seizure", along with epileptic discharges on the $\mathrm{EEG}^{17}$. Therefore, these headaches should be classified as ictal epileptic headache ${ }^{5}$. The headaches lasted $<35 \mathrm{~s}$ in all cases, which is also suggestive of ictal events ${ }^{17}$. A systematic review published in 2017 analysed 32 cases of reported ictal epileptic headache and found that the headache can be migraine-like or tension-type, and the location of the pain can vary ${ }^{53}$. The headaches occurred in children and adults and affected 
the sexes equally. Evidence from this and other studies indicates that the epileptic focus and EEG features of ictal epileptic headaches are heterogeneous ${ }^{52,53,55}$.

As in other focal epilepsies, in some individuals with ictal epileptic headache, epileptic abnormalities can only be detected with intracranial electrodes, suggesting a deep epileptic focus ${ }^{56}$. Ictal epileptic headache was identified in just five people in a retrospective review of 8,800 video-EEG recordings of 4,800 individuals with epilepsy ${ }^{57}$. Three of these five individuals had lesions in the left posterior regions, whereas the other two had generalised genetic or idiopathic epilepsy. A descriptive study of 47 people with epilepsy or unusual headache identified 22 individuals reporting headaches during seizures ${ }^{19}$. This high prevalence was attributed to the use of self-reports, and the absence of an objective tool to evaluate headache characteristics and accurately define the timing of headache onset relative to the seizure ${ }^{19}$. EEG recordings confirmed ictal headache in two individuals ${ }^{19}$. These studies and the definitions given in the ICHD-3 highlight the overlap between headaches and epilepsy. Atypical headaches - especially those with an abrupt onset and ending, or those that do not respond to analgesic treatment — should suggest to the clinician the possibility of an epileptic origin warranting an ictal EEG recording, especially if other suggestive features, such as a family history of epilepsy, are present. Paroxysmal episodes with visual signs can point to migraine with aura or epilepsy, and require detailed history taking. EEG recordings, ideally with concomitant video and encompassing the pre-ictal and ictal phase, are mandatory to support these challenging differential diagnoses and should be performed when the clinician has even the slightest suspicion that the headaches have an epileptic origin ${ }^{58}$.

\section{[H2] Post-ictal headaches}

Post-ictal headache is defined as a headache caused by an epileptic seizure, occurring $<3$ hours after the end of the seizure event and remitting spontaneously $<72$ hours after seizure termination ${ }^{5}$. Evidence indicates that postictal headache occurs in $<45 \%$ of individuals with epilepsy (Table 1), making it the most common type of periictal headache ${ }^{10-17,19,21}$. In $\sim 50 \%$ of individuals with post-ictal headache, the headache is migraine-like (Table 1) ${ }^{10-12,14-17}$. The results of a meta-analysis published in 2019 indicated that of individuals with epilepsy, one third experience post-ictal headache and $16 \%$ experience post-ictal migraine ${ }^{59}$. Interestingly, in people with focal epilepsy, post-ictal headache is more common in those with occipital epilepsy than those with epilepsy originating 
in the frontal or temporal lobes ${ }^{49}$. Post-ictal headache is also more common after convulsive seizures than after non-convulsive seizures ${ }^{35}$.

\section{[H1] Pathophysiology of headache disorders in epilepsy}

Comparing the pathophysiology of seizures and headache could help uncover the mechanisms underlying the observed associations between these two disorders. A neuronal excitation/inhibition imbalance is thought to contribute to attack susceptibility in epilepsy and migraine ${ }^{60-62}$. The link between hyperexcitability, seizures and cortical spreading depolarisation - the neurobiological correlate of the migraine aura and a putative trigger of migraine attacks - provides a mechanistic framework for some, but not all, of the clinical observations of headache in epilepsy (Box 2; Fig. 3).

\section{[H2] Mechanisms underlying seizures and headaches}

Epilepsy is characterised by a temporary disruption of neurological function caused by seizures, which spread across neuronal networks within seconds and are typically associated with hypersynchronous activity on EEG recordings ${ }^{63}$. This neuronal network synchronisation is thought to be caused by neuronal hyperexcitability ${ }^{64}$, which is likely to result from multiple factors. These factors include perinatal insults, impaired mitochondrial function and mutations in genes encoding ion channels or transporters that are involved in glutamatergic or GABAergic neuronal transmission or glial buffering capacity ${ }^{65-70}$.

Unlike seizures, headaches are not associated with hypersynchronous EEG activity, except in the case of headaches with an epileptic origin ${ }^{5,71,72}$. Headache is thought to result from activation of the trigeminovascular system, which involves meningeal nociceptive afferents from trigeminal ganglion sensory neurons, the brainstem trigeminal cervical complex (TCC), and thalamocortical areas contributing to the sensation of pain $^{73,74}$. Several factors can activate the trigeminovascular system at the meningeal level. These factors include the build-up of diffusible substances such as extracellular $\mathrm{K}^{+}$and $\mathrm{H}^{+}$(leading to low $\mathrm{pH}$ ), release of vasoactive mediators such as calcitonin gene-related peptide (CGRP) or substance $\mathrm{P}$, as well as inflammatory mechanisms ${ }^{74-76}$. The results of preclinical studies in rodents indicate that the trigeminovascular system can become activated by cortical spreading depolarisation ${ }^{77,78}$ and that this activation involves inflammatory cascades ${ }^{79,80}$. These observations 
suggest that cortical spreading depolarisation during migraine aura might initiate headache ${ }^{81}$ (Fig.3; but see also Box 2).

Meningeal vasodilation has been cited as trigger for trigeminovascular system activation, in line with the ancient 'vascular theory' of migraine, but more recent evidence suggests that changes to cerebral blood flow during a migraine attack are an accompanying phenomenon induced by trigeminal nerve activation ${ }^{82}$. In addition to the release of vasoactive substances from trigeminal nociceptive afferents, cerebral vasodilation could also result from activation of cardiovascular nuclei in the brainstem ${ }^{74}$. Neuroimaging studies have identified functional changes in the thalamic nuclei and brainstem, hypothalamus, frontal cortex, anterior cingulate cortex, basal ganglia, and insula during headache generation ${ }^{83,84}$. Connectivity changes in some of these regions have also been observed outside of and during attacks, as have changes affecting other regions such as the pons and somatosensory cortex ${ }^{85-89}$. Within this larger 'head pain matrix', hyperexcitability at any level could contribute to headache initiation ${ }^{74,76,90}$.

\section{[H2] Interictal headaches}

General brain hyperexcitability in people with epilepsy ${ }^{64}$ might, even in the absence of seizures, lower the activation thresholds of brain regions that are part of the trigeminovascular system, resulting in interictal headaches. This hyperexcitability can be a result of genetic mutations that affect neurotransmission (see section on overlapping genetics below) ${ }^{91}$. Studies in transgenic mouse models of migraine have identified an association between migraine-causing mutations and inflammatory changes ${ }^{92,93}$, which might also contribute to trigeminovascular system activation. In migraine, effects of exogenous triggers such as light or stress, food or sleep deprivation, and systemic fluctuations in sex hormones are hypothesized to contribute to attack initiation via the dysregulation of cortical and (hypo)thalamic pathways ${ }^{74,76,94-101}$. For example, in rats, bright-light stress causes cortical activation ${ }^{96}$, and sleep deprivation is associated with reduced brain glycogen levels and enhanced susceptibility to cortical spreading depolarization ${ }^{97,98}$. As hyperexcitability seems to contribute to the lowered threshold to headache triggers in migraine ${ }^{74,76}$, this could be hypothesized to also lead to an increased propensity for interictal headaches to occur in people with epilepsy.

\section{[H2] Pre-ictal headaches}


Brain parenchymal inflammation has been shown to promote seizure initiation in rodent models ${ }^{102,103}$. One mechanism underlying this inflammatory response involves the neuronal release of brain high mobility group box 1 (HMBG1) as a result of brain hyperexcitability ${ }^{104}$. In migraine headaches, activation of the trigeminovascular system by cortical spreading depolarization was shown to activate inflammatory cascades, including neuronal release of HMBG1, resulting in meningeal nociceptive activation ${ }^{79}$. It could be hypothesized that cortical network hyperexcitability, if maintained below the thresholds for eliciting epileptiform discharges and sensorimotor manifestations, could lead to trigeminovascular system activation via neuronal HMBG1 release.

At the subcortical level, pre-ictal hyperexcitability can affect central autonomic circuits, including hypothalamic and brainstem areas ${ }^{105}$, and projections to the limbic system ${ }^{106}$. Given the involvement of these areas in the development of head pain ${ }^{73,74}$, pre-ictal hyperexcitability in these regions could be hypothesized to elicit head pain before the development of widespread seizure activity.

\section{[H2] Migraine-aura triggered seizures}

The occurrence of a migraine aura before a seizure suggests an underlying cortical spreading depolarisation, followed by epileptiform activity. This sequence of events has been observed in preclinical studies, in which spreading depolarisation increased epileptic activity in rat brain slices ${ }^{107}$, as well as in resected human epileptic brain tissue ${ }^{107-110}$. Evidence indicates that suppression of inhibitory GABA function can contribute to this increase in epileptic activity ${ }^{107,110}$. Given the scarcity of clinical evidence for migraine aura-triggered seizures, this sequence of events is likely to be rare in humans. Indeed, the results of a preclinical study found that spreading depolarisation protected rat cortical networks from expressing seizure activity ${ }^{111}$.

\section{[H2] Ictal epileptic headache}

Multiple mechanisms could be responsible for ictal epileptic headache, including seizure-related changes in the trigeminovascular system and in pain-causing brain regions. The cortical projections responsible for head pain are likely to be widespread, involving primary sensory areas and the central autonomic network, that is, the thalamus, hypothalamus, insula, anterior cingulate cortex, medial prefrontal cortex, precuneus, amygdala, hippocampus and other parts of the limbic system ${ }^{54,72,112,113}$. A study in people with epilepsy evaluated participants' responses to direct electrical stimulation of the cortex during pre-surgical evaluation and showed that pain responses were scarce (observed for $1.4 \%$ of the stimulated sites). Pain was only triggered by stimulation 
of the medial parietal operculum and posterior insula ${ }^{114}$. This deep localisation of several pain areas might explain why, in some individuals, the electrophysiological correlate of ictal epileptic headache is only recorded using depth electrodes. However, seizures with a confirmed origin in the parietal operculum and posterior insula lead to pain sensations in the limbs contralateral to the epileptic focus and do not always lead to head or facial pain ${ }^{115}$. It is hypothesized that seizure activity in autonomous areas could cause direct neuronal activation of the brainstem trigeminocervical complex ${ }^{54}$ resulting in headache ${ }^{54,112,113}$, but direct evidence for this mechanism occurring in ictal epileptic headache is lacking.

A case series identified a multitude of EEG patterns in ictal epileptic headache ${ }^{52,53}$ suggesting that this form of headache is associated with different seizure types and localisations. As was suggested for pre-ictal headache, the mechanisms underlying ictal epileptic headache might also involve inflammatory changes caused by enhanced network excitability during seizures. However, in ictal epileptic headache, the timing of events triggering the trigeminovascular system occurs in parallel to the expression of symptomatic seizures and epileptiform EEG bursts. Increased cerebral blood flow during the pre-ictal and ictal period has also been suggested as a possible trigger of the trigeminovascular system, resulting in headache during seizures ${ }^{33}$. However, we do not consider this to be plausible as the results of magnetic resonance angiography studies in people with migraine indicate that arterial dilatation is an effect of headache, as opposed to a cause ${ }^{116,117}$. One such study found no evidence of arterial dilatation during migraine at all ${ }^{118}$. Indeed, the historical view of vasodilation as a cause of migraine headaches has now effectively been excluded ${ }^{74,82}$. In addition to the release of vasodilating substances from trigeminal nerve endings, vasodilation might also result from increased activity of the trigeminovascular system brainstem nuclei inducing vascular changes such as enhanced cerebral blood flow ${ }^{74}$. These observations suggest that an ictal epileptic headache is likely to result from direct activation of trigeminovascular system brainstem regions involved in headache generation, or seizure-related parenchymal changes triggering the activation of the trigeminovascular system.

\section{[H2] Post-ictal headaches}

Evidence from preclinical studies in rats indicates that seizures can be followed by spreading depolarisation ${ }^{119-}$ 122; however, post-ictal spreading depolarisation has not been observed in humans (except for studies in individuals with brain damage ${ }^{123,124}$ ) suggesting that this mechanism is not responsible for post-ictal headache. 
Experimental evidence also indicates that neurons do not remain depolarised after the termination of tonic-clonic seizures, but instead become hyperpolarized ${ }^{125}(\operatorname{Box} 2)$. This post-ictal neuronal silencing is sudden and widespread, instead of spreading ${ }^{126}$. Preclinical studies indicate that the mechanisms underlying post-ictal silencing are multifactorial ${ }^{126,127}$, including astrocytic adenosine release ${ }^{128}$, acidosis and hypoxia-related vesicular transmitter depletion ${ }^{128,129}$, none of which have been implicated in the initiation of spreading depolarization. There is no clinical evidence that post-ictal spreading depolarization contributes to post-ictal neuronal silencing (Box 2). In people with epilepsy, levels of adenosine were found to be enhanced post-ictally up to 18 minutes after seizures ${ }^{130}$, and post-ictal acidosis is evidenced from postictal hypercapnia ${ }^{131}$ and enhanced plasma levels of lactate $^{132}$. Clinical evidence for post-ictal neurotransmitter depletion is lacking ${ }^{133}$. Analysis of neocortical tissue from individuals with chronic epilepsy and a rat model of epilepsy suggested that the low likelihood of spreading depolarisation in epileptic tissue results from intrinsic changes in GABAergic transmission ${ }^{134}$.

Evidence from studies in rodent brain slices indicates that, even in the absence of post-ictal spreading depolarisation, excessive neuronal network activation during seizures can lead to trigeminovascular system activation via mechanisms such as the build-up of $\mathrm{K}^{+}$, acidosis and neuronal release of CGRP during or shortly after a seizure ${ }^{135-137}$. On the basis of evidence from preclinical studies, activation of meningeal nociceptive fibres by such compounds would be expected to lead to perception of headache by thalamocortical activation within $10-30$ minutes $^{74}$, in line with a post-ictal phenomenon. Inflammatory changes also occur during seizures ${ }^{102}$, for example, neuronal release of HMBG1 was shown to occur within an hour of seizure initiation in animal models ${ }^{104}$. It is possible that following seizures, these enhanced HMBG1 levels activate the trigeminovascular system (similar to the activation after spreading depolarization observed in experimental studies) causing post-ictal headache, although this hypothesis has not yet been tested in animals or humans. Last, seizures can yield postictal hypoperfusion as shown in rodent ${ }^{138}$ and some clinical epilepsy studies ${ }^{139,140}$. The resulting hypoxia ${ }^{138}$ might be sufficient to trigger headache mechanisms as occurs in hypoxia-induced migraine attacks ${ }^{141}$.

\section{[H1] Overlapping genetics}

Variants in $>200$ genes have been identified as causing or enhancing the risk of specific types of epilepsy ${ }^{142}$. Some monogenic forms of epilepsy exist, but for other epilepsies the genetic risk is complex and polygenic ${ }^{143}$. 
Juvenile myoclonic epilepsy has both a monogenetic and a complex genetic origin. In one study, $70 \%$ of people with this form of epilepsy reported a family history of migraine, almost twice as many as in an age-matched and sex-matched control group, suggesting an overlap in genetic risk between juvenile myoclonic epilepsy and migraine ${ }^{144}$.

Some specific genes have also been associated with both epilepsy and migraine ${ }^{66,145}$. This commonality is most evident in familial hemiplegic migraine (FHM), which is an autosomal dominant subtype of migraine with aura, characterised by a transient hemiparesis during the aura and headache characteristics that are identical to those observed in common forms of migraine ${ }^{146,147}$. Three genes have been associated with FHM: CACNA1A, which is located on chromosome 19p13 and encodes a subunit of neuronal voltage-gated $\mathrm{Ca}^{2+}$ channel $2.1\left(\mathrm{Ca}_{\mathrm{v}} 2.1\right)^{148}$; ATP1A2 ${ }^{149}$, which is located on chromosome 1q23 and encodes the $\alpha 2$ subunit of the glial $\mathrm{Na}^{+} / \mathrm{K}^{+}$-ATPase; and $S C N 1 A^{150}$, which is located on chromosome 2 q24 and encodes a subunit of neuronal voltage-gated sodium channel $1.1\left(\mathrm{Na}_{\mathrm{v}} 1.1\right)$. These three genes form the basis for the definition of three subtypes of FHM: mutations in CACNA1A cause FHM1, mutations in ATP1A2 cause FHM2 and mutation in SCN1A cause FHM3. For all three forms of FHM, specific mutations have been linked to specific presentations of migraine and epilepsy ${ }^{147,150-153}$. In FHM1 the 'mild' R192Q mutation in CACNA1A causes hemiplegic migraine without epileptic features ${ }^{148}$, whereas the more severe S218L mutation can also cause seizures ${ }^{152}$. In FHM2, novel missense mutations in ATP1A2 can result in the co-occurrence of migraine and childhood epilepsy ${ }^{151}$. In FHM3, different mutations in SCN1A have been be associated with either childhood epilepsy ${ }^{150}$ or generalised tonic-clonic seizures ${ }^{154}$. One study found that, in people with epilepsy and FHM3, generalized seizures occurred independently from hemiplegic migraine attacks ${ }^{154}$, suggesting that FHM and epilepsy share common molecular pathways.

Functional studies of FHM-associated mutations in vitro and in transgenic animal models have provided preclinical evidence that epilepsy and migraine result from partially overlapping genetic mechanisms ${ }^{155,156}$. These mechanisms involve alterations to neuronal and glial ion transport, resulting in network hyperexcitability ${ }^{61,146,155,157,158}$. Transgenic knock-in mice carrying the human FHM1-causing S218L mutation mimic the phenotype observed in humans with the mutation and display spontaneous or cortical spreading depolarisation-induced generalized seizures ${ }^{159,160}$. Results from in vitro studies suggest that the susceptibility for generalised seizures in FHM1 S218L mice is related to strongly enhanced excitatory transmission, resulting in 
excessive recruitment of excitatory and inhibitory neuronal networks ${ }^{161,162}$. In FHM3, the spectrum of Nav1.1 defects seems complex, and both gain-of-function and loss-of-function effects of mutations in SCN1A have been reported $^{163,164}$. The identification of gain-of-function effects of FHM3-associated mutations contrasts with the loss-of-function mutations in SCN1A that are associated with Dravet Syndrome and cause impaired firing of inhibitory interneurons ${ }^{165}$. Computational work indicates that dynamic changes in the activity of genetically affected excitatory and inhibitory neuronal networks, and associated changes in ion activity determine whether neuronal hyperexcitability may result in a seizure, a cortical spreading depolarisation, or $\operatorname{both}^{166}($ Box 2$)$. This observation underscores the complexity of predicting the functional outcome of shared genetic defects between epilepsy and migraine.

Truncating deletions in the PRRT2 gene, which encodes a proline-rich transmembrane protein, were identified in a small number of people with (hemiplegic) migraine ${ }^{167,168}$, as a result of which PRRT2 was put forward as the fourth FHM-associated gene. However, the same and similar PRRT2 deletions have been identified in people with paroxysmal kinesigenic dyskinesia, benign familial infantile convulsions and infantile convulsion choreoathetosis without signs of migraine ${ }^{147}$. Therefore, the relationship between PRRT2 and migraine does not seem to be precise.

A missense mutation in the $S L C 1 A 3$ gene, which encodes the glutamate transporter EAAT1 that is important in removing glutamate from the synaptic cleft $^{169}$, has been associated with severe episodes of ataxia, epileptic seizures and hemiplegic migraine that can be explained by impaired glutamate transport ${ }^{169}$. Other genetic findings associated with features of epilepsy and migraine include mutations in $P O L G$ and $C 10 o r F 2$, which encode mitochondrial DNA polymerase ${ }^{170}$ and Twinkle helicase ${ }^{171}$, respectively, and are involved in the maintenance of neuronal and glial energy supply. Some evidence suggests that mutations in mitochondrial genes associated with MELAS syndrome can predispose individuals to dysfunctional oxidative brain metabolism, explaining the cooccurrence of migraine-like episodes and epilepsy features in individuals with this syndrome ${ }^{172,173}$.

The genetic associations between polygenic forms of epilepsy and migraine remain unclear. However, a greater prevalence of migraine has been observed among family members of people with non-acquired focal epilepsy or generalised epilepsy than in the general population ${ }^{174}$, indicating a shared genetic susceptibility to both conditions. The results of a large-scale genome-wide association study identified a correlation between variants associated 
with migraine, especially migraine with aura, and variants associated with epilepsy; however, this correlation did not reach statistical significance ${ }^{175}$.

\section{[H1] Clinical management}

\section{[H2] Impact and diagnosis}

The results of a cross-sectional study indicated that $\sim 50 \%$ of individuals with headache and epilepsy report the headaches as severe ${ }^{21}$. Headaches linked to epilepsy negatively affect quality of life ${ }^{21}$. A study at an epilepsy clinic found that depression and anxiety were linked to the presence of headache ${ }^{15}$. Postictal headaches, in particular, were associated with depression and suicidality. The first step for successfully managing any condition is a correct diagnosis. The results of a Dutch questionnaire-based study found that neurologists underestimate the occurrence of headache among individuals with epilepsy ${ }^{28}$. This observation suggests that increased awareness among neurologists of the association between epilepsy and headache is required. Atypical or persistent headaches not responding to standard treatment should suggest a possible epileptic origin, warranting an EEGrecording during the symptomatic (headache or possible migraine aura) phase. We are not aware of published guidelines on managing headaches in people with epilepsy, so we summarize the current practice below, providing suggestions for managing headaches in people with epilepsy based on the currently available evidence and our expertise.

\section{[H2] Management of headaches in epilepsy}

Physicians managing the care of individuals with epilepsy should actively enquire about ictal, pre-ictal, and postictal headaches. An EEG recording of a headache event is mandatory to ascertain whether or not headaches have an epileptic origin, especially in the case of atypical, short-lasting and/or peri-ictal headaches ${ }^{19,45}$. Interictal and peri-ictal headaches that the individual reports as moderate or intense, once correctly diagnosed, should be treated with analgesics. If migraine is diagnosed concomitantly with epilepsy or vice-versa, an anti-seizure medication that also has proven efficacy for migraine should be prescribed whenever possible to avoid polypharmacy and possible drug - drug interactions ${ }^{176,177}$. The anti-seizure medications topiramate and valproate are approved for treatment of migraine by the FDA and European Medicines Agency ${ }^{178-180}$. However, topiramate and valproate can be teratogenic, so neither is suitable for treating women of child-bearing age ${ }^{181-183}$ unless there is no other 
effective treatment available ${ }^{179}$. Other anti-seizure medications, such as lamotrigine, can be used off-label, especially for migraine ${ }^{184}$.

Paradoxically, headaches are a common (>10\%) adverse-effect of anti-seizure medication, and are most often associated with carbamazepine, phenytoin, lamotrigine and levetiracetam ${ }^{185}$. When evaluating headache in epilepsy, the possibility of an adverse effect of medication should be considered. Lower doses of topiramate, valproate or lamotrigine are used for the treatment of migraine than for the treatment of epilepsy, but people with migraine still seem to be more prone to the adverse effects of these medications than people with epilepsy ${ }^{186}$. People with migraine or migraine and epilepsy are also more likely to discontinue medication than those with epilepsy alone ${ }^{186}$. Medications used for migraine have not been associated with seizures. Individuals with pharmacoresistant focal epilepsy can benefit from a resection of the epileptic focus; $34 \%-74 \%$ become seizurefree following the procedure ${ }^{187}$. However, in one study $12 \%$ of participants who underwent the procedure subsequently developed chronic headaches, which persisted for $>1$ year after surgery ${ }^{188}$.

\section{[H2] Novel pharmacological therapies}

Novel pharmacological therapies for migraine include those that target calcitonin gene-related peptide (CGRP), a trigeminal sensory neuropeptide that is expressed in neuronal tissue and distributed in discrete areas of the central and peripheral nervous system ${ }^{189}$. Although the precise mechanisms are unknown, activation of the trigeminovascular system seems to be associated with the increased release of CGRP from C-fibres in the trigeminal ganglion. Upon its release, CGRP binds to its receptor on A $\delta$-fibres, leading to pain perception ${ }^{190}$. The results of clinical trials of CGRP-inhibiting drugs in migraine have shown an efficacy that is superior to placebo, and generally good tolerability ${ }^{191}$, making these drugs an attractive new avenue for acute and prophylactic treatment of migraine. CGRP-inhibiting drugs hold particular promise for individuals with difficult-to-treat migraine, who have high unmet needs and few treatment options ${ }^{191-193}$. CGRP has vasodilatory effects and is important for blood pressure regulation ${ }^{189,194}$ and the long-term effects of CGRP-inhibition, especially in individuals with cardiovascular comorbidities, are still unknown ${ }^{195}$. Interestingly, the results of a study published in 2018 indicate that the new anti-seizure medication perampanel, which acts on glutamatergic 
AMPA receptors, inhibits CGRP release in rat brainstem ${ }^{196}$. This observation suggests that perampanel could, in theory, be effective in treating peri-ictal headaches, although this has not been investigated yet.

Cannabidiol has received considerable media attention ${ }^{197-199}$ after a case report indicated that it can reduce seizure frequency in individuals with epilepsy ${ }^{200}$. The results of clinical trials in Dravet syndrome ${ }^{201-203}$ and LennoxGastaut syndrome $\mathrm{e}^{204,205}$ suggest that cannabidiol is more effective than placebo in reducing the frequency of convulsive and drop seizures ${ }^{206}$. Additional open-label studies of cannabidiol in other types of epilepsy are ongoing $^{207-209}$. An oral cannabidiol solution has been approved by the FDA $^{210}$ and the European Medicines Agency $^{211}$ for treatment of seizures in children aged 2 years and older with Dravet syndrome and Lennox-Gastaut syndrome, two rare forms of severe epilepsy. One trial to assess the effect of cannabis on migraine is ongoing ${ }^{212}$ and another is planned ${ }^{213}$.

\section{[H2] Non-pharmacological approaches}

A meta-analysis of studies on transcranial magnetic stimulation (TMS) found that low-frequency TMS was associated with a reduction in seizure frequency in $30 \%$ of participants with treatment-resistant epilepsy ${ }^{214}$. The studies included in this analysis were, however, relatively small and heterogeneous, so more evidence to support this approach is needed. A systematic review of TMS for the treatment of headache disorders found that stimulation was associated with reduced headache frequency, duration, intensity and medication use; however, few studies reported TMS-associated changes greater than those observed with sham treatment ${ }^{215}$. Several studies have found an association between treatment with single-pulse TMS and a reduction in headache days and medication use in individuals with migraine with aura ${ }^{216-218}$. This evidence led the FDA to approve a single-pulse TMS device for the acute treatment of this type of migraine ${ }^{219}$. Evidence from a study using a rat model of migraine suggests that the effect of TMS on headache involves the suppression of cortical excitability, including the cortical spreading depolarisation that underlies the aura phase ${ }^{220}$. Clinical trials have found non-invasive stimulation of the trigeminal nerve to be moderately effective for acute migraine treatment ${ }^{221}$ and prevention ${ }^{222}$. Non-invasive stimulation of the vagus nerve was highly effective for acute migraine treatment ${ }^{223}$ but ineffective for migraine prevention ${ }^{224}$. In three small randomized controlled trials ( $<<150$ in each study) this form of vagus nerve stimulation was also shown to be effective in drug-resistant epilepsy ${ }^{225-227}$. 
Evidence is emerging that therapeutic education, including the provision of information on lifestyle factors such as sleep and alcohol consumption as well as behavioural, self-management and mind-body approaches can have beneficial effects for individuals with chronic conditions, including headache ${ }^{228,229}$, migraine $e^{230-232}$ and epilepsy $^{233,234}$. Although therapeutic education approaches do not cure these conditions, they can help individuals cope with the associated psychological burden. The ILAE recently recommended the widespread implementation of such techniques for people with epilepsy ${ }^{233}$.

\section{[H1] Conclusions and future challenges}

Clear evidence exists for an association between headaches and epilepsy. The results of studies published in the last five years have confirmed that headaches, especially migraines, often co-occur with epilepsy. This observation is in keeping with the growing body of evidence that comorbidity and multi-morbidity are common in neurological conditions ${ }^{235,236}$. Highlighting this overlap during neurological and medical training should help neurologists and general physicians be more attentive to the association between headaches and epilepsy. The gap between headache and epilepsy classifications highlights the need for closer collaboration between specialists, within departments and between professional bodies such as the ILAE and IHS. Such partnership could lead to the development of standardised questionnaires to aid the diagnosis of headache in epilepsy and guidelines on the management of comorbid headache and epilepsy. These diagnostic tools and guidelines will help improve the treatment, care, and management of these complex conditions.

To improve our understanding of the nature of the association between epilepsy and headache, and to establish the direction of this association, thorough longitudinal studies in large, multi-centric cohorts will be vital. Additional research efforts aimed at elucidating the pathophysiological mechanisms underlying headache in epilepsy and improving the management of these conditions are also needed. Although the pathophysiological mechanisms underlying epilepsy and migraine are highly complex, animal models of comorbidity ${ }^{103,237}$ will help uncover the mechanistic links between activation of the trigeminovascular system and epilepsy.

In conclusion, headaches, and epilepsy are not separate disease entities but seem to be symptoms of altered neuronal network excitability. Ultimately, it will be important to elucidate the various, likely multifactorial, 
causes underlying the different epilepsy-headache constellations thus enabling the development of aetiological diagnostic classifications and corresponding therapies.

\section{References}

1. Fisher, R. S. et al. ILAE Official Report: A practical clinical definition of epilepsy. Epilepsia 55, 475482 (2014).

2. GBD 2016 Epilepsy Collaborators. Global, regional, and national burden of epilepsy, $1990-2016$ : a systematic analysis for the Global Burden of Disease Study 2016. Lancet Neurol. 18, 357-375 (2019).

3. Scheffer, I. E. et al. ILAE classification of the epilepsies: Position paper of the ILAE Commission for Classification and Terminology. Epilepsia 58, 512-521 (2017).

4. GBD 2017 Disease and Injury Incidence and Prevalence Collaborators. Global, regional, and national incidence, prevalence, and years lived with disability for 354 diseases and injuries for 195 countries and territories, 1990-2017: a systematic analysis for the Global Burden of Disease Study 2017. Lancet 392, 1789-1858 (2018).

5. Headache Classification Committee of the International Headache Society (IHS). The International Classification of Headache Disorders, 3rd edition. Cephalalgia 38, 1-211 (2018).

6. Goadsby, P. J. Pathophysiology of migraine. Neurol Clin 27, 335-360 (2009).

7. Naeije, G., Gaspard, N., Legros, B. \& Mavroudakis, N. Transient CNS deficits and migrainous auras in individuals without a history of headache. Headache 54, 493-499 (2014).

8. Keezer, M. R., Bauer, P. R., Ferrari, M. D. \& Sander, J. W. The comorbid relationship between migraine and epilepsy : a systematic review and meta-analysis. Eur J Neurol 22, 1038-1047 (2014).

9. Duko, B., Ayalew, M. \& Toma, A. The epidemiology of headaches among patients with epilepsy: a systematic review and meta-analysis. J. Headache Pain 21, 3 (2020).

10. Çilliler, A. E., Güven, H. \& Çomoğlu, S. S. Epilepsy and headaches: Further evidence of a link. Epilepsy Behav. 70, 161-165 (2017).

11. Wang, X. qing et al. Comorbidity between headache and epilepsy in a Chinese epileptic center. Epilepsy 
Res. 108, 535-541 (2014).

12. Mainieri, G. et al. Headache in epilepsy: prevalence and clinical features. J. Headache Pain 16, 1-10 (2015).

13. Hofstra, W., Hageman, G. \& de Weerd, A. Periictal and interictal headache including migraine in Dutch patients with epilepsy: a cross-sectional study. Epilepsy Behav. 44, 155-158 (2015).

14. Mutlu, A. Association between epilepsy and headache. Neurol. Sci. 39, 2129-2134 (2018).

15. Seo, J. H., Joo, E. Y., Seo, D. W. \& Hong, S. B. Correlation between headaches and affective symptoms in patients with epilepsy. Epilepsy Behav. 60, 204-208 (2016).

16. Whealy, M. A., Myburgh, A., Bredesen, T. J. \& Britton, J. W. Headache in epilepsy: A prospective observational study. Epilepsia Open 4, 593-598 (2019).

17. Kim, D. W., Sunwoo, J. S. \& Lee, S. K. Headache as an Aura of Epilepsy: Video-EEG Monitoring Study. Headache 56, 762-768 (2016).

18. Begasse de Dhaem, O. A. J. et al. Migraine comorbidity and cognitive performance in patients with focal epilepsy. Epilepsy Behav. 97, 29-33 (2019).

19. Salma, Z. et al. Headaches and their relationships to epileptic seizures. Epilepsy Behav. 90, 233-237 (2019).

20. Wilner, A. N., Sharma, B. K., Soucy, A., Thompson, A. \& Krueger, A. Common comorbidities in women and men with epilepsy and the relationship between number of comorbidities and health plan paid costs in 2010. Epilepsy Behav. 32, 15-20 (2014).

21. Mameniškienė, R., Karmonaitè, I. \& Zagorskis, R. The burden of headache in people with epilepsy. Seizure 41, 120-126 (2016).

22. Bernasconi, A., Andermann, F., Bernasconi, N., Reutens, D. C. C. \& Dubeau, F. Lateralizing value of peri-ictal headache: A study of 100 patients with partial epilepsy. Neurology 56, 130-132 (2001).

23. Belcastro, V., Striano, P. \& Parisi, P. "Ictal epileptic headache": Beyond the epidemiological evidence. Epilepsy Behav. 25, 9-10 (2012).

24. Keezer, M. R., Bouma, H. K. \& Wolfson, C. The diagnostic accuracy of screening questionnaires for the identification of adults with epilepsy: A systematic review. Epilepsia 55, 1772-1780 (2014).

25. Dugan, P. et al. Auras in generalized epilepsy. Neurology 83, 1444-1449 (2014). 
26. Delgado-Rodriguez, M. Bias. J. Epidemiol. Community Heal. 58, 635-641 (2004).

27. Belcastro, V., Striano, P., Kasteleijn-Nolst Trenité, D. G. A., Villa, M. P. \& Parisi, P. Migralepsy, hemicrania epileptica, post-ictal headache and 'ictal epileptic headache': a proposal for terminology and classification revision. J Headache Pain 12, 289-294 (2011).

28. Hofstra, W. A., Hageman, G. \& De Weerd, A. W. Headache in epilepsy patients: The (un)awareness of this phenomenon among Dutch neurologists. Seizure 25, 37-39 (2015).

29. Parisi, P. et al. Diagnostic criteria currently proposed for 'ictal epileptic headache': Perspectives on strengths, weaknesses and pitfalls. Seizure 31, 56-63 (2015).

30. Harnod, T., Wang, Y. C. \& Kao, C. H. High risk of developing subsequent epilepsy in young adults with migraine: A nationwide population-based cohort study in Taiwan. Qjm 108, 449-455 (2015).

31. Harnod, T., Wang, Y. C. \& Tseng, C. H. Male, old age and low income to predispose epilepsy in migraineurs. Eur. J. Clin. Invest. 47, 63-72 (2017).

32. Leniger, T., Isbruch, K., Von Den Driesch, S., Diener, H. C. \& Hufnagel, A. Seizure-Associated Headache in Epilepsy. Epilepsia 42, 1176-1179 (2002).

33. Yankovsky, A. E., Andermann, F. \& Bernasconi, A. Characteristics of headache associated with intractable partial epilepsy. Epilepsia 46, 1241-1245 (2005).

34. Förderreuther, S., Henkel, A., Noachtar, S. \& Straube, A. Headache Associated with Epileptic Seizures: Epidemiology and Clinical Characteristics. Headache J. Head Face Pain 42, 649-655 (2002).

35. Karaali-Savrun, F., Göksan, B., Naz Yeni, S., Ertan, S. \& Uzun, N. Seizure-related headache in patients with epilepsy. Seizure 11, 67-69 (2002).

36. Blume, W. T. et al. Glossary of Descriptive Terminology for Ictal Semiology: Report of the ILAE Task Force on Classification and Terminology. Epilepsia 42, 1212-1218 (2002).

37. Lieb, J., Walsh, G., Babb, T., Walter, R. \& Crandall, P. A comparison of EEG seizure patterns recorded with surface and depth electrodes in patients with temporal lobe epilepsy. Epilepsia 17, 137-60 (1976).

38. de Tommaso, M. An update on EEG in migraine. Expert Rev. Neurother. 19, 729-737 (2019).

39. Bjork, M., Stovner, L. J., Hagen, K. \& Sand, T. What initiates a migraine attack? Conclusions from four longitudinal studies of quantitative EEG and steady-state visual-evoked potentials in migraineurs. Acta Neurol Scand Suppl 56-63 (2011). doi:10.1111/j.1600-0404.2011.01545.x 
40. Sand, T. EEG in migraine: a review of the literature. Funct. Neurol. 6, 7-22 (1991).

41. Sand, T. Electroencephalography in Migraine: A Review with Focus on Quantitative Electroencephalography and the Migraine Vs. Epilepsy Relationship. Cephalalgia 23, 5-11 (2003).

42. Viana, M., Tronvik, E. A., Do, T. P., Zecca, C. \& Hougaard, A. Clinical features of visual migraine aura: a systematic review. J. Headache Pain 20, 64 (2019).

43. Adcock, J. E. \& Panayiotopoulos, C. P. Occipital lobe seizures and epilepsies. J Clin Neurophysiol 29, 397-407 (2012).

44. Saitowitz, Z., Flamini, R. \& Berenson, F. Ictal Epileptic Headache: A Review of Current Literature and Differentiation From Migralepsy and Other Epilepsies. Headache J. Head Face Pain 54, 1534-1540 (2014).

45. Hartl, E., Angel, J., Rémi, J., Schankin, C. J. \& Noachtar, S. Visual Auras in Epilepsy and Migraine An Analysis of Clinical Characteristics. Headache 57, 908-916 (2017).

46. Verrotti, A. et al. Should "migralepsy" be considered an obsolete concept? A multicenter retrospective clinical/EEG study and review of the literature. Epilepsy Behav. 21, 52-59 (2011).

47. Verrotti, A. et al. Migralepsy and related conditions: advances in pathophysiology and classification. Seizure 20, 271-275 (2011).

48. Hartl, E., Rémi, J., Noachtar, S., Remi, J. \& Noachtar, S. Two Patients With Visual Aura - Migraine, Epilepsy, or Migralepsy? Headache 55, 1148-1151 (2015).

49. Wang, X. qing et al. High prevalence of headaches in patients with epilepsy. J. Headache Pain 15, 1-10 (2014).

50. Fanella, M. et al. Clinical Correspondence: A Case of Ictal Epileptic Headache in Non Convulsive Status. Headache 59, 1090-1092 (2019).

51. Parisi, P. et al. 'Ictal epileptic headache': recent concepts for new classifications criteria. Cephalalgia 32, 723-724 (2012).

52. Parisi, P., Striano, P., Verrotti, A., Villa, M. P. \& Belcastro, V. What have we learned about ictal epileptic headache? A review of well-documented cases. Seizure 22, 253-258 (2013).

53. Cianchetti, C., Dainese, F., Ledda, M. G. \& Avanzini, G. Epileptic headache: A rare form of painful seizure. Seizure 52, 169-175 (2017). 
54. Parisi, P. et al. Ictal Epileptic Headache: When Terminology Is Not a Moot Question. Front. Neurol. 10, $1-6(2019)$.

55. Coci, E. G. \& Riedel, J. Exploring two novel cases of suspected ictal epileptic headache, a rare form of paediatric epilepsy. Acta Paediatr. 106, 786-790 (2017).

56. Siegel, A. M., Williamson, P. D., Roberts, D. W., Thadani, V. M. \& Darcey, T. M. Localized Pain Associated with Seizures Originating in the Parietal Lobe. Epilepsia 40, 845-855 (1999).

57. Fanella, M. et al. Ictal epileptic headache in adult life: Electroclinical patterns and spectrum of related syndromes. Epilepsy Behav. 53, 161-165 (2015).

58. Parisi, P., Belcastro, V., Verrotti, A., Striano, P. \& Kasteleijn-Nolst Trenitè, D. G. A. "Ictal epileptic headache" and the revised International Headache Classification (ICHD-3) published in Cephalalgia 2018, vol. 38(1) 1-211: Not just a matter of definition! Epilepsy Behav. 87, 243-245 (2018).

59. Subota, A. et al. Signs and symptoms of the postictal period in epilepsy: A systematic review and metaanalysis. Epilepsy Behav. 94, 243-251 (2019).

60. Nye, B. L. \& Thadani, V. M. Migraine and epilepsy: review of the literature. Headache 55, 359-380 (2015).

61. Bauer, P. R. et al. Headache and epilepsy. Curr Pain Headache Rep 17, 351-360 (2013).

62. Parisi, P. et al. Hypothesis on neurophysiopathological mechanisms linking epilepsy and headache. Med Hypotheses 70, 1150-1154 (2008).

63. Jefferys, J. G. R. Advances in understanding basic mechanisms of epilepsy and seizures. Seizure 19, $638-646(2010)$.

64. Staley, K. Molecular mechanisms of epilepsy. Nat Neurosci 18, 367-372 (2015).

65. Janigro, D. \& Walker, M. C. What non-neuronal mechanisms should be studied to understand epileptic seizures? Adv Exp Med Biol 813, 253-264 (2014).

66. Spillane, J., Kullmann, D. M. \& Hanna, M. G. Genetic neurological channelopathies: molecular genetics and clinical phenotypes. J Neurol Neurosurg Psychiatry 87, 37-48 (2016).

67. Whittaker, R. G. et al. Epilepsy in adults with mitochondrial disease: A cohort study. Ann. Neurol. 78, 949-957 (2015).

68. Boison, D. \& Steinhäuser, C. Epilepsy and astrocyte energy metabolism. Glia 66, 1235-1243 (2018). 
69. Kovács, R. et al. Bioenergetic Mechanisms of Seizure Control. Front. Cell. Neurosci. 12, (2018).

70. Carrasco, M. \& Stafstrom, C. E. How Early Can a Seizure Happen? Pathophysiological Considerations of Extremely Premature Infant Brain Development. Dev. Neurosci. 40, 417-436 (2018).

71. Magis, D. et al. Pearls and pitfalls: electrophysiology for primary headaches. Cephalalgia 33, 526-539 (2013).

72. Tolner, E. A., Chen, S. P. \& Eikermann-Haerter, K. Current understanding of cortical structure and function in migraine. Cephalalgia 39, 1683-1699 (2019).

73. Burstein, R., Noseda, R. \& Borsook, D. Migraine: multiple processes, complex pathophysiology. $J$ Neurosci 35, 6619-6629(2015).

74. Goadsby, P. J. et al. Pathophysiology of Migraine: A Disorder of Sensory Processing. Physiol Rev 97, $553-622(2017)$.

75. Romero-Reyes, M. \& Akerman, S. Update on Animal Models of Migraine. Curr. Pain Headache Rep. 18, $462(2014)$.

76. Brennan, K. C. \& Pietrobon, D. A Systems Neuroscience Approach to Migraine. Neuron 97, 1004-1021 (2018).

77. Zhang, X. et al. Activation of meningeal nociceptors by cortical spreading depression: implications for migraine with aura. $J$ Neurosci 30, 8807-8814 (2010).

78. Zhang, X. et al. Activation of central trigeminovascular neurons by cortical spreading depression. Ann Neurol 69, 855-865 (2011).

79. Karatas, H. et al. Spreading depression triggers headache by activating neuronal Panx1 channels. Science (80-. ). 339, 1092-1095 (2013).

80. Schain, A. J. et al. Activation of pial and dural macrophages and dendritic cells by cortical spreading depression. Ann Neurol 83, 508-521 (2018).

81. Hadjikhani, N. et al. Mechanisms of migraine aura revealed by functional MRI in human visual cortex. Proc Natl Acad Sci U S A 98, 4687-4692 (2001).

82. Mason, B. N. \& Russo, A. F. Vascular Contributions to Migraine: Time to Revisit? Front Cell Neurosci $12,233(2018)$.

83. Schwedt, T. J., Chiang, C. C., Chong, C. D. \& Dodick, D. W. Functional MRI of migraine. Lancet 
Neurol 14, 81-91 (2015).

84. Schulte, L. H. \& May, A. Of generators, networks and migraine attacks. Curr Opin Neurol 30, 241-245 (2017).

85. Chong, C. D., Schwedt, T. J. \& Hougaard, A. Brain functional connectivity in headache disorders: A narrative review of MRI investigations. J Cereb Blood Flow Metab 39, 650-669 (2019).

86. Skorobogatykh, K. et al. Functional connectivity studies in migraine: What have we learned? $J$. Headache Pain 20, (2019).

87. Coppola, G. et al. Resting state connectivity between default mode network and insula encodes acute migraine headache. Cephalalgia 38, 846-854 (2018).

88. Amin, F. M. et al. Altered thalamic connectivity during spontaneous attacks of migraine without aura: A resting-state fMRI study. Cephalalgia 38, 1237-1244 (2018).

89. Hougaard, A., Amin, F. M., Larsson, H. B., Rostrup, E. \& Ashina, M. Increased intrinsic brain connectivity between pons and somatosensory cortex during attacks of migraine with aura. Hum Brain Mapp 38, 2635-2642 (2017).

90. Vecchia, D. \& Pietrobon, D. Migraine: a disorder of brain excitatory-inhibitory balance? Trends Neurosci 35, 507-520 (2012).

91. Myers, C. T. \& Mefford, H. C. Advancing epilepsy genetics in the genomic era. Genome Med 7, 91 (2015).

92. Franceschini, A. et al. TNFalpha levels and macrophages expression reflect an inflammatory potential of trigeminal ganglia in a mouse model of familial hemiplegic migraine. PLoS One 8, e52394 (2013).

93. Eising, E. et al. Cortical Spreading Depression Causes Unique Dysregulation of Inflammatory Pathways in a Transgenic Mouse Model of Migraine. Mol Neurobiol 54, 2986-2996 (2017).

94. Borsook, D. et al. Sex and the migraine brain. Neurobiol Dis 68, 200-214 (2014).

95. Lipton, R. B. et al. Reduction in perceived stress as a migraine trigger: testing the 'let-down headache' hypothesis. Neurology 82, 1395-1401 (2014).

96. Becerra, L. et al. Triptans disrupt brain networks and promote stress-induced CSD-like responses in cortical and subcortical areas. J Neurophysiol 115, 208-217 (2016).

97. Negro, A. et al. Acute sleep deprivation enhances susceptibility to the migraine substrate cortical 
spreading depolarization. J. Headache Pain 21, 86 (2020).

98. Kilic, K. et al. Inadequate brain glycogen or sleep increases spreading depression susceptibility. Ann. Neurol. 83, 61-73 (2018).

99. Martins-Oliveira, M. et al. Neuroendocrine signaling modulates specific neural networks relevant to migraine. Neurobiol. Dis. 101, 16-26 (2017).

100. Eikermann-Haerter, K. et al. Enhanced subcortical spreading depression in familial hemiplegic migraine type 1 mutant mice. J Neurosci 31, 5755-5763 (2011).

101. van Casteren, D. S., Verhagen, I. E., Onderwater, G. L., MaassenVanDenBrink, A. \& Terwindt, G. M. Sex differences in prevalence of migraine trigger factors: A cross-sectional study. Cephalalgia (2020). doi:10.1177/0333102420974362

102. Vezzani, A. Epilepsy and inflammation in the brain: overview and pathophysiology. Epilepsy Curr 14, $3-7$ (2014).

103. Fan, S., Xiao, Z., Zhu, F., He, X. \& Lu, Z. A new comorbidity model and the common pathological mechanisms of migraine and epilepsy. Am. J. Transl. Res. 9, 2286-2295 (2017).

104. Ravizza, T. et al. High Mobility Group Box 1 is a novel pathogenic factor and a mechanistic biomarker for epilepsy. Brain. Behav. Immun. 72, 14-21 (2018).

105. Nagai, Y. Modulation of autonomic activity in neurological conditions: Epilepsy and Tourette Syndrome. Front Neurosci 9, 278 (2015).

106. Bartolomei, F. et al. Pre-ictal synchronicity in limbic networks of mesial temporal lobe epilepsy. Epilepsy Res. 61, 89-104 (2004).

107. Krüger, H. et al. Repetitive spreading depression causes selective suppression of GABAergic function. Neuroreport 7, 2733-2736 (1996).

108. Gorji, A. \& Speckmann, E. J. Spreading depression enhances the spontaneous epileptiform activity in human neocortical tissues. Eur J Neurosci 19, 3371-3374 (2004).

109. Berger, M., Speckmann, E. J., Pape, H. C. \& Gorji, A. Spreading depression enhances human neocortical excitability in vitro. Cephalalgia 28, 558-562 (2008).

110. Eickhoff, M. et al. Spreading depression triggers ictaform activity in partially disinhibited neuronal tissues. Exp. Neurol. 253, 1-15 (2014). 
111. Zakharov, A., Chernova, K., Burkhanova, G., Holmes, G. L. \& Khazipov, R. Segregation of seizures and spreading depolarization across cortical layers. Epilepsia 60, 2386-2397 (2019).

112. Sklerov, M., Dayan, E. \& Browner, N. Functional neuroimaging of the central autonomic network: recent developments and clinical implications. Clin. Auton. Res. 29, 555-566 (2019).

113. Beissner, F., Meissner, K., Bär, K. J. \& Napadow, V. The autonomic brain: An activation likelihood estimation meta-analysis for central processing of autonomic function. J. Neurosci. 33, 10503-10511 (2013).

114. Mazzola, L., Isnard, J., Peyron, R. \& Mauguire, F. Stimulation of the human cortex and the experience of pain: Wilder Penfield's observations revisited. Brain 135, 631-640 (2012).

115. Montavont, A. et al. On the origin of painful somatosensory seizures. Neurology 84, 594-601 (2015).

116. Amin, F. M. et al. Magnetic resonance angiography of intracranial and extracranial arteries in patients with spontaneous migraine without aura: a cross-sectional study. Lancet Neurol 12, 454-461 (2013).

117. Khan, S. et al. Meningeal contribution to migraine pain: a magnetic resonance angiography study. Brain 142, 93-102 (2019).

118. Schoonman, G. G. et al. Migraine headache is not associated with cerebral or meningeal vasodilatation-a 3 T magnetic resonance angiography study. Brain 131, 2192-2200 (2008).

119. Koroleva, V. I. \& Bures, J. Cortical penicillin focus as a generator of repetitive spike-triggered waves of spreading depression in rats. Exp Brain Res 51, 291-297 (1983).

120. Mody, I., Lambert, J. D. \& Heinemann, U. Low extracellular magnesium induces epileptiform activity and spreading depression in rat hippocampal slices. J Neurophysiol 57, 869-888 (1987).

121. Vinogradova, L. V. Comparative potency of sensory-induced brainstem activation to trigger spreading depression and seizures in the cortex of awake rats: Implications for the pathophysiology of migraine aura. Cephalalgia 35, 979-986 (2015).

122. Haglund, M. M. \& Schwartzkroin, P. A. Role of Na-K pump potassium regulation and IPSPs in seizures and spreading depression in immature rabbit hippocampal slices. J. Neurophysiol. 63, 225-239 (1990).

123. Dreier, J. P. et al. Spreading convulsions, spreading depolarization and epileptogenesis in human cerebral cortex. Brain 135, 259-275 (2012).

124. Fabricius, M. et al. Association of seizures with cortical spreading depression and peri-infarct 
depolarisations in the acutely injured human brain. Clin Neurophysiol 119, 1973-1984 (2008).

125. Kandel, E. R. \& Spencer, W. A. Excitation and inhibition of single pyramidal cells during hippocampal seizure. Exp Neurol 4, 162-179 (1961).

126. Bauer, P. R. et al. Dynamics of convulsive seizure termination and postictal generalized EEG suppression. Brain 140, 655-668 (2017).

127. Pottkämper, J. C. M., Hofmeijer, J., van Waarde, J. A. \& van Putten, M. J. A. M. The postictal state What do we know? Epilepsia 61, 1045-1061 (2020).

128. Boison, D. Adenosine and seizure termination: endogenous mechanisms. Epilepsy Curr 13, 35-37 (2013).

129. Fleidervish, I. A., Gebhardt, C., Astman, N., Gutnick, M. J. \& Heinemann, U. Enhanced spontaneous transmitter release is the earliest consequence of neocortical hypoxia that can explain the disruption of normal circuit function. $J$ Neurosci 21, 4600-4608 (2001).

130. During, M. J. \& Spencer, D. D. Adenosine: a potential mediator of seizure arrest and postictal refractoriness. Ann Neurol 32, 618-624 (1992).

131. Kennedy, J. D. \& Seyal, M. Respiratory Pathophysiology With Seizures and Implications for Sudden Unexpected Death in Epilepsy. J. Clin. Neurophysiol. 32, 10-13 (2015).

132. Nass, R. D., Zur, B., Elger, C. E., Holdenrieder, S. \& Surges, R. Acute metabolic effects of tonic-clonic seizures. Epilepsia Open 4, 599-608 (2019).

133. Fisher, R. S. \& Schachter, S. C. The Postictal State: A Neglected Entity in the Management of Epilepsy. Epilepsy Behav. 1, 52-59 (2000).

134. Kohling, R. et al. Differential sensitivity to induction of spreading depression by partial disinhibition in chronically epileptic human and rat as compared to native rat neocortical tissue. Brain Res 975, 129-134 (2003).

135. Tozzi, A. et al. Critical role of calcitonin gene-related peptide receptors in cortical spreading depression. Proc Natl Acad Sci U S A 109, 18985-18990 (2012).

136. Raimondo, J. V, Burman, R. J., Katz, A. A. \& Akerman, C. J. Ion dynamics during seizures. Front Cell Neurosci 9, 419 (2015).

137. Barbarosie, M., Louvel, J., Kurcewicz, I. \& Avoli, M. CA3-Released Entorhinal Seizures Disclose 
Dentate Gyrus Epileptogenicity and Unmask a Temporoammonic Pathway. J. Neurophysiol. 83, 1115$1124(2000)$.

138. Farrell, J. S. et al. Postictal behavioural impairments are due to a severe prolonged hypoperfusion/hypoxia event that is COX-2 dependent. Elife 5, (2016).

139. Weinand, M. E. et al. Cerebral blood flow and temporal lobe epileptogenicity. J. Neurosurg. 86, 226232 (1997).

140. Phillips, T. J., Gom, R. C., Wolff, M. D. \& Teskey, G. C. Caffeine Exacerbates Postictal Hypoxia. Neuroscience 422, 32-43 (2019).

141. Arngrim, N. et al. Migraine induced by hypoxia: an MRI spectroscopy and angiography study. Brain 139, $723-737$ (2016).

142. Myers, K. A., Johnstone, D. L. \& Dyment, D. A. Epilepsy genetics: Current knowledge, applications, and future directions. Clin. Genet. 95, 95-111 (2019).

143. Noebels, J. L. Single-gene models of epilepsy. Adv Neurol 79, 227-238 (1999).

144. Dedei Daryan, M. et al. Prevalence and clinical characteristics of headache in juvenile myoclonic epilepsy: experience from a tertiary epilepsy center. Neurol. Sci. 39, 519-525 (2018).

145. Prontera, P. et al. Epilepsy in hemiplegic migraine: Genetic mutations and clinical implications. Cephalalgia 38, 361-373 (2018).

146. Haan, J., van den Maagdenberg, A. M., Brouwer, O. F. \& Ferrari, M. D. Migraine and epilepsy: genetically linked? Expert Rev Neurother 8, 1307-1311 (2008).

147. Pelzer, N. et al. Clinical spectrum of hemiplegic migraine and chances of finding a pathogenic mutation. Neurology 90, e575-e582 (2018).

148. Ophoff, R. et al. Familial hemiplegic migraine and episodic ataxia type-2 are caused by mutations in the Ca2+ channel gene CACNL1A4. Cell 87, 543-552 (1996).

149. De Fusco, M. et al. Haploinsufficiency of ATP1A2 encoding the $\mathrm{Na}+\mathrm{K}+$ pump alpha2 subunit associated with familial hemiplegic migraine type 2. Nat Genet 33, 192-196 (2003).

150. Dichgans, M. et al. Mutation in the neuronal voltage-gated sodium channel SCN1A in familial hemiplegic migraine. Lancet 366, 371-377 (2005).

151. Vanmolkot, K. R. et al. Novel mutations in the Na+, K+-ATPase pump gene ATP1A2 associated with 
familial hemiplegic migraine and benign familial infantile convulsions. Ann Neurol 54, 360-366 (2003).

152. Stam, A. H. et al. Early seizures and cerebral oedema after trivial head trauma associated with the CACNA1A S218L mutation. J Neurol Neurosurg Psychiatry 80, 1125-1129 (2009).

153. Chirchiglia, D. et al. Hemiplegic migraine and late-onset photosensitive epileptic seizures. Neurol. Sci. 37, 2009-2011 (2016).

154. Castro, M. J. et al. First mutation in the voltage-gated Nav1.1 subunit gene SCN1A with co-occurring familial hemiplegic migraine and epilepsy. Cephalalgia 29, 308-313 (2009).

155. Chen, S. P., Tolner, E. A. \& Eikermann-Haerter, K. Animal models of monogenic migraine. Cephalalgia 36, 704-721 (2016).

156. Ferrari, M. D., Klever, R. R., Terwindt, G. M., Ayata, C. \& van den Maagdenberg, A. M. J. M. Migraine pathophysiology: lessons from mouse models and human genetics. Lancet Neurol 14, 65-80 (2015).

157. Bianchin, M. M., Londero, R. G., Lima, J. E. \& Bigal, M. E. Migraine and epilepsy: a focus on overlapping clinical, pathophysiological, molecular, and therapeutic aspects. Curr Pain Headache Rep 14, 276-283 (2010).

158. Rogawski, M. A. Migraine and Epilepsy-Shared Mechanisms within the Family of Episodic Disorders. in Jasper's Basic Mechanisms of the Epilepsies (eds. Noebels, J. L., Avoli, M., Rogawski, M. A., Olsen, R. W. \& Delgado-Escueta, A. V) (2012).

159. Eikermann-Haerter, K. et al. Genetic and hormonal factors modulate spreading depression and transient hemiparesis in mouse models of familial hemiplegic migraine type 1. J Clin Invest 119, 99-109 (2009).

160. van den Maagdenberg, A. M. J. M. et al. High cortical spreading depression susceptibility and migraineassociated symptoms in Ca(v)2.1 S218L mice. Ann. Neurol. 67, 85-98 (2010).

161. Vecchia, D., Tottene, A., van den Maagdenberg, A. M. \& Pietrobon, D. Mechanism underlying unaltered cortical inhibitory synaptic transmission in contrast with enhanced excitatory transmission in CaV2.1 knockin migraine mice. Neurobiol Dis 69, 225-234 (2014).

162. Vecchia, D., Tottene, A., van den Maagdenberg, A. M. \& Pietrobon, D. Abnormal cortical synaptic transmission in CaV2.1 knockin mice with the S218L missense mutation which causes a severe familial hemiplegic migraine syndrome in humans. Front Cell Neurosci 9, 8 (2015).

163. Kahlig, K. M. et al. Divergent sodium channel defects in familial hemiplegic migraine. Proc Natl Acad 
Sci U S A 105, 9799-9804 (2008).

164. Bertelli, S., Barbieri, R., Pusch, M. \& Gavazzo, P. Gain of function of sporadic/familial hemiplegic migraine-causing SCN1 A mutations: Use of an optimized cDNA. Cephalalgia 39, 477-488 (2019).

165. Yu, F. H. et al. Reduced sodium current in GABAergic interneurons in a mouse model of severe myoclonic epilepsy in infancy. Nat Neurosci 9, 1142-1149 (2006).

166. Wei, Y., Ullah, G. \& Schiff, S. J. Unification of neuronal spikes, seizures, and spreading depression. $J$ Neurosci 34, 11733-11743 (2014).

167. Riant, F. et al. De novo mutations in ATP1A2 and CACNA1A are frequent in early-onset sporadic hemiplegic migraine. Neurology 75, 967-972 (2010).

168. Meneret, A. et al. PRRT2 mutations and paroxysmal disorders. Eur J Neurol 20, 872-878 (2013).

169. Jen, J. C., Wan, J., Palos, T. P., Howard, B. D. \& Baloh, R. W. Mutation in the glutamate transporter EAAT1 causes episodic ataxia, hemiplegia, and seizures. Neurology 65, 529-534 (2005).

170. Tzoulis, C. et al. The spectrum of clinical disease caused by the A467T and W748S POLG mutations: a study of 26 cases. Brain 129, 1685-1692 (2006).

171. Lonnqvist, T., Paetau, A., Valanne, L. \& Pihko, H. Recessive twinkle mutations cause severe epileptic encephalopathy. Brain 132, 1553-1562 (2009).

172. Kuwajima, M. et al. MELAS syndrome with $\mathrm{m} .4450 \mathrm{G}$ \&gt; A mutation in mitochondrial tRNAMet gene. Brain Dev. 41, 465-469 (2019).

173. El-Hattab, A. W., Adesina, A. M., Jones, J. \& Scaglia, F. MELAS syndrome: Clinical manifestations, pathogenesis, and treatment options. Mol. Genet. Metab. 116, 4-12 (2015).

174. Winawer, M. R., Connors, R. \& Investigators, E. Evidence for a shared genetic susceptibility to migraine and epilepsy. Epilepsia 54, 288-295 (2013).

175. The Brainstorm Consortium. Analysis of shared heritability in common disorders of the brain. Science (80-. ). 13, eaap8757 (2018).

176. Zaccara, G. \& Perucca, E. Interactions between antiepileptic drugs, and between antiepileptic drugs and other drugs. Epileptic Disord. 16, 409-431 (2014).

177. Patsalos, P. N. \& Perucca, E. Clinically important drug interactions in epilepsy: Interactions between antiepileptic drugs and other drugs. Lancet Neurol. 2, 473-481 (2003). 
178. Marmura, M. J. \& Kumpinsky, A. S. Refining the Benefit/Risk Profile of Anti-Epileptic Drugs in Headache Disorders. CNS Drugs 32, 735-746 (2018).

179. European Medicine Agency. Available at: https://www.ema.europa.eu/en/medicines/human/referrals/valproate-related-substances-0. (Accessed: 21st February 2021)

180. European Medicines Agency on Topiramate. Available at: https://www.ema.europa.eu/en/medicines/human/referrals/topamax. (Accessed: 21st February 2021)

181. Tomson, T. et al. Valproate in the treatment of epilepsy in girls and women of childbearing potential. Epilepsia 56, 1006-1019 (2015).

182. Hernandez-Diaz, S. et al. Topiramate use early in pregnancy and the risk of oral clefts. Neurology $\mathbf{9 0}$, e342-e351 (2018).

183. Vatzaki, E. et al. Latest clinical recommendations on valproate use for migraine prophylaxis in women of childbearing age: overview from European Medicines Agency and European Headache Federation. $J$. Headache Pain 19, 68 (2018).

184. Buch, D. \& Chabriat, H. Lamotrigine in the Prevention of Migraine With Aura: A Narrative Review. Headache J. Head Face Pain 59, 1187-1197 (2019).

185. Nevitt, S., Sudell, M., Weston, J., Tudur Smith, C. \& Marson, A. Antiepileptic drug monotherapy for epilepsy: A network meta-analysis of individual participant data. Cochrane Database Syst. Rev. 6, (2017).

186. Romoli, M. et al. Antiepileptic drugs in migraine and epilepsy: Who is at increased risk of adverse events? Cephalalgia 38, 274-282 (2018).

187. Jobst, B. C. \& Cascino, G. D. Resective epilepsy surgery for drug-resistant focal epilepsy. JAMA 313, $285-293$ (2015).

188. Kaur, A., Selwa, L., Fromes, G. \& Ross, D. A. Persistent headache after supratentorial craniotomy. Neurosurgery 47, 633-636 (2000).

189. Russell, F. A., King, R., Smillie, S.-J., Kodji, X. \& Brain, S. D. Calcitonin Gene-Related Peptide: Physiology and Pathophysiology. Physiol. Rev. 94, 1099-1142 (2014).

190. Haanes, K. A. \& Edvinsson, L. Pathophysiological Mechanisms in Migraine and the Identification of 
New Therapeutic Targets. CNS Drugs 33, 525-537 (2019).

191. Ferrari, M. D. et al. Fremanezumab versus placebo for migraine prevention in patients with documented failure to up to four migraine preventive medication classes (FOCUS): a randomised, double-blind, placebo-controlled, phase 3b trial. Lancet 394, 1030-1040 (2019).

192. Edvinsson, L., Haanes, K. A., Warfvinge, K. \& Krause, D. N. CGRP as the target of new migraine therapies - successful translation from bench to clinic. Nat. Rev. Neurol. 14, 338-350 (2018).

193. Charles, A. \& Pozo-Rosich, P. Targeting calcitonin gene-related peptide: a new era in migraine therapy. Lancet 394, 1765-1774 (2019).

194. Deng, P.-Y. \& Li, Y.-J. Calcitonin gene-related peptide and hypertension. Peptides 26, 1676-1685 (2005).

195. Deen, M. et al. Blocking CGRP in migraine patients - a review of pros and cons. J. Headache Pain 18, $1-9$ (2017).

196. Tringali, G., Currò, D. \& Navarra, P. Perampanel inhibits calcitonin gene-related peptide release from rat brainstem in vitro. J. Headache Pain 19, 107 (2018).

197. Gupta, S. CNN: How medical marijuana changed Charlotte Figi’s daily life (2014). (2014). Available at: https://edition.cnn.com/videos/bestoftv/2014/08/01/robin-hoods-of-marijuana.cnn. (Accessed: 20th February 2021)

198. Kollewe, J. Cannabis-based drug for childhood epilepsy approved for use in UK. The Guardian (2019).

199. Velasquez-Manoff, M. Can CBD Really Do All That? How one molecule from the cannabis plant came to be seen as a therapeutic cure-all. The New York Times Magazine (2019).

200. Maa, E. \& Figi, P. The case for medical marijuana in epilepsy. Epilepsia 55, 783-786 (2014).

201. Devinsky, O. et al. Trial of Cannabidiol for Drug-Resistant Seizures in the Dravet Syndrome. $N$ Engl $J$ Med 376, 2011-2020 (2017).

202. Devinsky, O. et al. Randomized, dose-ranging safety trial of cannabidiol in Dravet syndrome. Neurology 90, e1204-e1211 (2018).

203. Devinsky, O. et al. Long-term cannabidiol treatment in patients with Dravet syndrome: An open-label extension trial. Epilepsia 60, 294-302 (2019).

204. Thiele, E. et al. Cannabidiol in patients with Lennox-Gastaut syndrome: Interim analysis of an open- 
label extension study. Epilepsia 60, 419-428 (2019).

205. Devinsky, O. et al. Effect of Cannabidiol on Drop Seizures in the Lennox-Gastaut Syndrome. N. Engl. J. Med. 378, 1888-1897 (2018).

206. O’Connell, B. K., Gloss, D. \& Devinsky, O. Cannabinoids in treatment-resistant epilepsy: A review. Epilepsy Behav. 70, 341-348 (2017).

207. Ingram, J. B. Cannabidiol for Drug Resistant Pediatric Epilepsy (Expanded Access Use) (Clinicaltrial.gov NCT03676049). Available at: https://clinicaltrials.gov/ct2/show/NCT03676049. (Accessed: 21st February 2021)

208. Phillips, S. Expanded Use of Cannabidiol Oral Solution (Clinicaltrial.gov NCT03196934). Available at: https://clinicaltrials.gov/ct2/show/NCT03196934. (Accessed: 22nd February 2021)

209. Park, Y. Epidiolex and Drug Resistant Epilepsy in Children (CBD) (Clinicaltrials.gov NCT02397863). Available at: https://clinicaltrials.gov/ct2/show/NCT02397863. (Accessed: 22nd February 2021)

210. Felberbaum, M. FDA Approves First Drug Comprised of an Active Ingredient Derived from Marijuana to Treat Rare, Severe Forms of Epilepsy. (2018). Available at: https://www.fda.gov/news-events/pressannouncements/fda-approves-first-drug-comprised-active-ingredient-derived-marijuana-treat-raresevere-forms.

211. EMA decision on Epidyolex. Available at: https://www.ema.europa.eu/en/medicines/human/EPAR/epidyolex. (Accessed: 23rd February 2021)

212. Schuster, N. Efficacy of Inhaled Cannabis for Acute Migraine Treatment (Clinicaltrial.gov NCT04360044). Available at: https://clinicaltrials.gov/ct2/show/NCT04360044. (Accessed: 23rd February 2021)

213. Amoozegar, F. Cannabis for the Prophylactic Treatment of Migraine (Clinicaltrial.gov NCT03972124).

214. Cooper, Y. A. et al. Repetitive transcranial magnetic stimulation for the treatment of drug-resistant epilepsy: A systematic review and individual participant data meta-analysis of real-world evidence. Epilepsia Open 3, 55-65 (2017).

215. Stilling, J. M., Monchi, O., Amoozegar, F. \& Debert, C. T. Transcranial Magnetic and Direct Current Stimulation (TMS/tDCS) for the Treatment of Headache: A Systematic Review. Headache 59, 339-357 (2019). 
216. Lipton, R. B. et al. Single-pulse transcranial magnetic stimulation for acute treatment of migraine with aura: a randomised, double-blind, parallel-group, sham-controlled trial. Lancet Neurol 9, 373-380 (2010).

217. Starling, A. J. et al. A multicenter, prospective, single arm, open label, observational study of sTMS for migraine prevention (ESPOUSE Study). Cephalalgia 38, 1038-1048 (2018).

218. Lan, L., Zhang, X., Li, X., Rong, X. \& Peng, Y. The efficacy of transcranial magnetic stimulation on migraine: a meta-analysis of randomized controlled trails. J. Headache Pain 18, (2017).

219. US FDA. Transcranial magnetic stimulator for the treatment of migraine headache (K140094). (2014).

220. Andreou, A. P. et al. Transcranial magnetic stimulation and potential cortical and trigeminothalamic mechanisms in migraine. Brain 139, 2002-2014 (2016).

221. Chou, D. E. et al. Acute migraine therapy with external trigeminal neurostimulation (ACME): A randomized controlled trial. Cephalalgia 39, 3-14 (2019).

222. Schoenen, J. et al. Migraine prevention with a supraorbital transcutaneous stimulator: A randomized controlled trial. Neurology 80, 697-704 (2013).

223. Tassorelli, C. et al. Noninvasive vagus nerve stimulation as acute therapy for migraine. Neurology $\mathbf{9 1}$, e364-e373 (2018).

224. Silberstein, S. D. et al. Chronic migraine headache prevention with noninvasive vagus nerve stimulation. Neurology 87, 529-538 (2016).

225. Aihua, L. et al. A controlled trial of transcutaneous vagus nerve stimulation for the treatment of pharmacoresistant epilepsy. Epilepsy Behav. 39, 105-110 (2014).

226. Rong, P. et al. Transcutaneous vagus nerve stimulation for refractory epilepsy: a randomized controlled trial. Clin. Sci. (2014). doi:10.1042/CS20130518

227. Bauer, S. et al. Transcutaneous Vagus Nerve Stimulation (tVNS) for Treatment of Drug-Resistant Epilepsy: A Randomized, Double-Blind Clinical Trial (cMPsE02). Brain Stimul. 9, 356-363 (2016).

228. Lee, H. J., Lee, J. H., Cho, E. Y., Kim, S. M. \& Yoon, S. Efficacy of psychological treatment for headache disorder: A systematic review and meta-analysis. J. Headache Pain 20, (2019).

229. Probyn, K. et al. Non-pharmacological self-management for people living with migraine or tension-type 
headache: A systematic review including analysis of intervention components. BMJ Open 7, 1-12 (2017).

230. Simshäuser, K., Lüking, M., Kaube, H., Schultz, C. \& Schmidt, S. Is Mindfulness-Based Stress Reduction a Promising and Feasible Intervention for Patients Suffering from Migraine? A Randomized Controlled Pilot Trial. Complement. Med. Res. 27, 19-30 (2020).

231. Seng, E. K. et al. Does Mindfulness-Based Cognitive Therapy for Migraine Reduce Migraine-Related Disability in People with Episodic and Chronic Migraine? A Phase 2b Pilot Randomized Clinical Trial. Headache J. Head Face Pain 59, 1448-1467 (2019).

232. Wells, R. E., Beuthin, J. \& Granetzke, L. Complementary and Integrative Medicine for Episodic Migraine: an Update of Evidence from the Last 3 Years. Curr. Pain Headache Rep. 23, 1-10 (2019).

233. Michaelis, R. et al. Psychological treatments for adults and children with epilepsy: Evidence-based recommendations by the International League Against Epilepsy Psychology Task Force. Epilepsia 59, 1282-1302 (2018).

234. Haut, S. R. et al. Behavioral interventions as a treatment for epilepsy. Neurology 90, e963-e970 (2018).

235. Hesdorffer, D. C. Comorbidity between neurological illness and psychiatric disorders. CNS Spectr. 21, 230-238 (2016).

236. Boison, D. \& Aronica, E. Comorbidities in Neurology: Is adenosine the common link? Neuropharmacology 97, 18-34 (2015).

237. Kros, L., Lykke-Hartmann, K. \& Khodakhah, K. Increased susceptibility to cortical spreading depression and epileptiform activity in a mouse model for FHM2. Sci. Rep. 8, 16959 (2018).

238. Somjen, G. G. Mechanisms of spreading depression and hypoxic spreading depression-like depolarization. Physiol Rev 81, 1065-1096 (2001).

239. Lauritzen, M. et al. Clinical relevance of cortical spreading depression in neurological disorders: migraine, malignant stroke, subarachnoid and intracranial hemorrhage, and traumatic brain injury. $J$ Cereb Blood Flow Metab 31, 17-35 (2011).

240. Enger, R. et al. Dynamics of Ionic Shifts in Cortical Spreading Depression. Cereb Cortex 25, 4469$4476(2015)$.

241. Kramer, D. R., Fujii, T., Ohiorhenuan, I. \& Liu, C. Y. Interplay between Cortical Spreading 
Depolarization and Seizures. Stereotact Funct Neurosurg 95, 1-5 (2017).

242. So, N. K. \& Blume, W. T. The postictal EEG. Epilepsy Behav 19, 121-126 (2010).

243. Lhatoo, S. D. et al. An electroclinical case-control study of sudden unexpected death in epilepsy. Ann Neurol 68, 787-796 (2010).

244. Surges, R., Strzelczyk, A., Scott, C. A., Walker, M. C. \& Sander, J. W. Postictal generalized electroencephalographic suppression is associated with generalized seizures. Epilepsy Behav 21, 271$274(2011)$.

245. Lhatoo, S. D. et al. An electroclinical case-control study of sudden unexpected death in epilepsy. Ann Neurol 68, 787-796 (2010).

246. Sarkis, R. A. et al. Autonomic changes following generalized tonic clonic seizures: An analysis of adult and pediatric patients with epilepsy. Epilepsy Res. 115, 113-118 (2015).

247. Bolay, H. et al. Intrinsic brain activity triggers trigeminal meningeal afferents in a migraine model. Nat Med 8, 136-142 (2002).

248. Dreier, J. P. \& Reiffurth, C. The stroke-migraine depolarization continuum. Neuron 86, 902-922 (2015).

249. Jackson J. (1875) Hospital for the epileptic and paralyzed: Case illustrating the relation between certain cases of migraine and epilepsy. Lancet.;106:244-245.

250. Gowers WR. (1906) Clinical Lectures on the borderland of epilepsy. III Migraine.Br Med J.;2:16171622

251. Lennox WG, Lennox MA. (1960) Epilepsy and related disorders. Boston: Little, Brown \& Company, Boston.

252. Laplante P, Saint-Hilaire JM, Bouvier G (1983). Headache as an epileptic manifestation. Neurology.33(11):1493-1493.

253. Andermann F. (1987) Migraine-epilepsy relationships Epilepsy Res. 1: 213-226

254. Schon F, Blau JN. (1987) Post-epileptic headache and migraine. J Neurol Neurosurg Psychiatry. Sep;50(9):1148-52. doi: 10.1136/jnnp.50.9.1148

255. Hablitz JJ, Heinemann U. (1989) Alterations in the microenvironment during spreading depression associated with epileptiform activity in the immature neocortex. Brain Res Dev Brain Res. 1989 Apr 1;46(2):243-52. doi: 10.1016/0165-3806(89)90288-5. 
256. Ottman, R. \& Lipton, R.B. (1994) Comorbidity of migraine and epilepsy. Neurology 44: 2105-2110

257. Herreras O, Largo C, Ibarz JM, Somjen GG, Martín del Río R. (1994) Role of neuronal synchronizing mechanisms in the propagation of spreading depression in the in vivo hippocampus. J Neurosci. 14(11 Pt 2):7087-7098.

258. Panayiotopoulos CP. (1999) Visual phenomena and headache in occipital epilepsy: a review, a systematic study and differentiation from migraine. Epileptic Disord. 1:205-216.

259. Gorji A, Scheller D, Straub H, Tegtmeier F, Köhling R, Höhling JM, Tuxhorn I, Ebner A, Wolf P, Werner Panneck H, Oppel F, Speckmann EJ. (2001) Spreading depression in human neocortical slices. Brain Res. 6:74-83. doi: 10.1016/s0006-8993(01)02557-4

260. Leniger T, von den Driesch S, Isbruch K, Diener HC, Hufnagel A. (2003) Clinical characteristics of patients with comorbidity of migraine and epilepsy. Headache.43:672-7. doi: 10.1046/j.15264610.2003.03111.x.

261. Rogawski MA, Löscher W. (2004) The neurobiology of antiepileptic drugs for the treatment of nonepileptic conditions. Nat Med. 10(7):685-92. doi: 10.1038/nm1074. PMID: 15229516.

262. Welch KM. (2005) Brain hyperexcitability: the basis for antiepileptic drugs in migraine prevention. Headache. 45 Suppl 1:S25-32. doi: 10.1111/j.1526-4610.2005.4501008.x.

263. Haut SR, Bigal ME, Lipton RB. (2006) Chronic disorders with episodic manifestations: focus on epilepsy and migraine. Lancet Neurol.5:148-157. doi: 10.1016/S1474-4422(06)70348-9.

264. Cai S, Hamiwka LD, Wirrell EC. (2008) Peri-Ictal Headache in Children: Prevalence and Character. Pediatr Neurol;39(2):91-6.

\section{Acknowledgements}

P. R. B. is funded by the Berta Ottenstein program of the University of Freiburg, Germany. This work was partly undertaken at NIHR University College London Hospitals Comprehensive Bio-Medical Research Centre, which received a proportion of funding from the Department of Health's Research Centres funding scheme. M. D. F. receives research support from the Dutch national science prize, Spinoza Award. E. A. T. receives research support from a grant from Dutch National Science Foundation (NWO-ZonMW, project "Brain@home”). J. W. S. receives research support from the Dr. Marvin Weil Epilepsy Research Fund and UK Epilepsy Society. 


\section{Competing interests}

1116

M. R. K. reports advisory fees for Eisai, Elsevier, Novartis, Sage Therapeutics, Sunovion, and UCB; unrestricted educational grants from Eisai and UCB; and research grants from Eisai and UCB. J. W. S. has been consulted by and received fees for lectures from Arvelle, Eisai, UCB Pharma and Zogenix. The other authors declare no competing interests.

\section{Review criteria}

We searched PubMed for articles with the MeSH terms and keywords "headache", "migraine" "epilepsy" and "treatment" in the title, abstract or keywords. The search focused on primary studies published in the last 5 years (April 2015 - April 2020). Additional articles were identified from the authors' own files and from chosen bibliographies. The articles in this Review were included at the authors' discretion on the basis of originality and relevance of the publication. Selected key works from before 2015 are shown in figure 1.

Informed consent

The authors affirm that human research participants provided informed consent for publication of the video in Supplementary Video 1.

\section{Key points}

- The lifetime prevalence of migraine is $52 \%$ greater in individuals with epilepsy than in individuals witho epilepsy.

- The symptoms of epilepsy and headache can present diagnostic challenges; a detailed history and EEG recordi of the epileptic and/or headache event are important for classification and management.

- Enhanced neuronal excitability might be the mechanistic link between headaches and seizures.

- Several genetic mutations can cause epilepsy and migraine, but the genetic association between polygenic for of epilepsy and migraine remains unclear. 
- Novel therapies include calcitonin gene-related peptide-blocking drugs for migraine and neuromodulative non-pharmacological approaches for migraine and epilepsy; behavioural and selfmanagement approaches are increasing in popularity. 


\begin{tabular}{|c|c|c|c|c|c|c|c|c|c|c|c|}
\hline \multirow[t]{2}{*}{ Study } & \multirow{2}{*}{$\begin{array}{l}\text { Cohort size } \\
\text { and type }\end{array}$} & \multirow{2}{*}{$\begin{array}{l}\text { Case } \\
\text { ascertainm } \\
\text { ent }\end{array}$} & \multicolumn{9}{|c|}{ Number reporting headache } \\
\hline & & & Total & $\begin{array}{l}\text { Pre- } \\
\text { ictal }\end{array}$ & Ictal & Post-ictal & $\begin{array}{l}\text { Inter- } \\
\text { ictal }\end{array}$ & $\begin{array}{l}\text { Inte } \\
\text { r- } \\
\text { ictal } \\
\text { and } \\
\text { pre- } \\
\text { ictal }\end{array}$ & $\begin{array}{l}\text { Pre } \\
- \\
\text { icta } \\
\text { l } \\
\text { and } \\
\text { pos } \\
\text { t- } \\
\text { icta } \\
\text { l }\end{array}$ & $\begin{array}{l}\text { Post- } \\
\text { ictal } \\
\text { and } \\
\text { inter- } \\
\text { ictal }\end{array}$ & $\begin{array}{l}\text { Pre- } \\
\text { ictal } \\
\text { post } \\
- \\
\text { ictal } \\
\text { and } \\
\text { inte } \\
\text { r- } \\
\text { ictal }\end{array}$ \\
\hline $\begin{array}{l}\text { Begasse de } \\
\text { Dhaem } \\
2019^{18}\end{array}$ & $\begin{array}{l}349(209 \\
\text { female }) ; \\
\text { new-onset } \\
\text { focal } \\
\text { epilepsy }\end{array}$ & $\begin{array}{l}\text { Validated } \\
\text { headache } \\
\text { questionnair } \\
\text { e (ICHD) }\end{array}$ & $\begin{array}{l}74 \\
(21.2 \\
\%) \\
\text { migrai } \\
\text { ne }\end{array}$ & NA & NA & NA & $\mathrm{NA}$ & NA & $\mathrm{NA}$ & NA & NA \\
\hline $\begin{array}{l}\text { Çililer } \\
2017^{10}\end{array}$ & $\begin{array}{l}349(190 \\
\text { female); } \\
\text { consecutive } \\
\text { epilepsy } \\
\text { cases (69 } \\
\text { partial } \\
\text { seizures; } 209 \\
\text { generalised } \\
\text { seizures; } 71 \\
\text { secondary } \\
\text { generalised } \\
\text { seizures) }\end{array}$ & $\begin{array}{l}\text { Interview } \\
\text { with } \\
\text { questionnair } \\
\text { e (ICHD-2) }\end{array}$ & $\begin{array}{l}152 \\
(94 \\
\text { MI; } 60 \\
\text { TTH; } \\
43 \text { U) }\end{array}$ & $\begin{array}{l}19(12 \\
\text { MI; } 4 \\
\text { TTH; } \\
3 \mathrm{U})\end{array}$ & NA & $\begin{array}{l}82(30 \\
\text { MI; } 25 \\
\text { TTH, } 27 \\
\text { U) }\end{array}$ & $\begin{array}{l}17(8 \\
\text { MI; } \\
7 \mathrm{TTH}, \\
2 \mathrm{U})\end{array}$ & NA & 33 & 26 & 16 \\
\hline $\begin{array}{l}\text { Hofstra } \\
2015^{13}\end{array}$ & $\begin{array}{l}255(126 \\
\text { female }) \\
\text { cross- } \\
\text { sectional }\end{array}$ & $\begin{array}{l}\text { Questionnai } \\
\text { re, ICHD-2 } \\
\text { criteria }\end{array}$ & $\begin{array}{l}186 \\
(65 \\
\text { MI; } 97 \\
\text { TTH; } \\
15 \text { U) }\end{array}$ & 3 & NA & 28 & 92 & NA & NA & NA & NA \\
\hline Kim $2016^{17}$ & $\begin{array}{l}831(391 \\
\text { female); } \\
\text { consecutive } \\
\text { video EEG } \\
\text { cases ( } 775 \\
\text { partial } \\
\text { seizures; } 55 \\
\text { generalised } \\
\text { seizures) }\end{array}$ & $\begin{array}{l}\text { Epileptic } \\
\text { aura } \\
\text { description, } \\
\text { follow-up } \\
\text { by phone } \\
\text { interview } \\
\text { ( } 457 \text { no } \\
\text { aura; } 374 \\
\text { with aura) }\end{array}$ & NA & $\begin{array}{l}25 \text { (all } \\
\text { partial } \\
\text { seizure } \\
\text { s) }\end{array}$ & $\begin{array}{l}6(2 \\
\text { hemicra } \\
\text { nia } \\
\text { epileptic } \\
\text { a, } 4 \text { R- } \\
\text { TLE, 1 } \\
\text { L-TLE, } \\
1 \\
\text { Central } \\
\text { seizure) }\end{array}$ & $\begin{array}{l}257(238 \\
\text { partial } ; \\
18 \\
\text { generalis } \\
\text { ed) }\end{array}$ & NA & NA & NA & NA & NA \\
\hline $\begin{array}{l}\text { Mainieri } \\
2015^{12}\end{array}$ & $\begin{array}{l}388 \text { (209 } \\
\text { female); } \\
\text { consecutive } \\
\text { cases with } \\
\text { epilepsy (101 } \\
\text { generalised } \\
\text { epilepsy; } 280 \\
\text { focal } \\
\text { epilepsy; } 7 \\
\text { U) }\end{array}$ & $\begin{array}{l}\text { Self-report } \\
\text { and } \\
\text { structured } \\
\text { interview }\end{array}$ & 209 & $\begin{array}{l}26(16 \\
\text { MI; } 5 \\
\text { TTH; } \\
5 \\
\text { other) }\end{array}$ & 3 & $\begin{array}{l}74(37 \\
\text { MI; } 30 \\
\text { TTH) }\end{array}$ & $\begin{array}{l}188 \\
(102 \\
\mathrm{MI}^{\mathrm{d}} \text {; } \\
74 \\
\mathrm{TTH} ; \\
2 \\
\text { cluster } \\
; 9 \mathrm{U})\end{array}$ & NA & NA & NA & NA \\
\hline $\begin{array}{l}\text { Mameniški } \\
\text { enè } 2016^{21}\end{array}$ & $\begin{array}{l}289(172 \\
\text { female) ; } \\
\text { adults with } \\
\text { epilepsy } \\
\text { treated in } \\
\text { epilepsy } \\
\text { center }\end{array}$ & $\begin{array}{l}\text { Self-report } \\
\text { and } \\
\text { structured } \\
\text { interview }\end{array}$ & $\begin{array}{l}233 \\
(69 \\
\text { MI, } \\
85 \mathrm{TT} \\
\text { H, 79 } \\
\text { other) }\end{array}$ & 23 & 1 & 46 & $\begin{array}{l}\begin{array}{l}218 \\
(69\end{array} \\
\text { MI, } 85 \\
\text { TTH, } \\
52 \\
\text { other }\end{array}$ & NA & NA & NA & NA \\
\hline
\end{tabular}




\begin{tabular}{|c|c|c|c|c|c|c|c|c|c|c|c|}
\hline $\begin{array}{l}\text { Mutlu } \\
2018^{14}\end{array}$ & $\begin{array}{l}420^{c} ; \\
\text { consecutive } \\
\text { outpatient } \\
\text { cases }\end{array}$ & $\begin{array}{l}\text { Interview } \\
\text { (ICHD) }\end{array}$ & $\begin{array}{l}111 \\
(63 \\
\mathrm{MI})\end{array}$ & $\begin{array}{l}29(9 \\
\mathrm{MI})\end{array}$ & NA & $32(5 \mathrm{MI})$ & $\begin{array}{l}83(58 \\
\mathrm{MI})\end{array}$ & $\begin{array}{l}15 \\
(5 \\
M I)\end{array}$ & $\begin{array}{l}17 \\
(3 \\
\mathrm{MI})\end{array}$ & NA & NA \\
\hline $\begin{array}{l}\text { Salma } \\
2019^{19}\end{array}$ & $\begin{array}{l}47(28 \\
\text { female); } \\
\text { cases with } \\
\text { epilepsy or } \\
\text { unusual } \\
\text { headache (33 } \\
\text { focal } \\
\text { epilepsy; } 6 \\
\text { generalised } \\
\text { epilepsy; } 8 \\
\text { U) }\end{array}$ & $\begin{array}{l}\text { Interview } \\
\text { (ICHD) }\end{array}$ & 37 & 2 & $\begin{array}{l}22(5 \\
\text { isolated } \\
\left.\mathrm{IEH}^{\mathrm{a}}\right)\end{array}$ & $\begin{array}{l}10 \text { (focal } \\
\text { seizures) }\end{array}$ & 15 & NA & NA & NA & NA \\
\hline Seo $2016^{15}$ & $\begin{array}{l}177(85 \\
\text { female); } \\
\text { consecutive } \\
\text { individuals } \\
\text { with epilepsy } \\
\text { diagnosis }\end{array}$ & Interview & 73 & $\begin{array}{l}3(1 \\
\mathrm{MI})\end{array}$ & NA & $\begin{array}{l}48(17 \\
\text { MI; } 24 \\
\text { TTH; } 7 \text { U } \\
)\end{array}$ & 34 & NA & NA & NA & NA \\
\hline $\begin{array}{l}\text { Wang } \\
2014^{11}\end{array}$ & $\begin{array}{l}1109(502 \\
\text { female) } \\
\text { (856 partial } \\
\text { seizures; } 195 \\
\text { generalised } \\
\text { seizures; } 58 \\
\text { unclassified } \\
\text { seizures) }\end{array}$ & $\begin{array}{l}\text { Questionnai } \\
\text { re, then } \\
\text { interview } \\
\text { (ICHD) }\end{array}$ & 667 & $\begin{array}{l}59(38 \\
\mathrm{MI})\end{array}$ & NA & $\begin{array}{l}469(314 \\
\text { MI) }\end{array}$ & $\begin{array}{l}231 \\
(139 \\
\text { MI) }\end{array}$ & NA & 9 & $\begin{array}{l}45 \\
\text { (interict } \\
\text { al } \\
\text { migrain } \\
\text { e) }\end{array}$ & 9 \\
\hline $\begin{array}{l}\text { Whealy } \\
2019^{16}\end{array}$ & $\begin{array}{l}120 \text { (67 } \\
\text { female);epile } \\
\text { psy } \\
\text { monitoring } \\
\text { unit }\end{array}$ & $\begin{array}{l}\text { Questionnai } \\
\text { re (ICHD 3) }\end{array}$ & NA & NA & NA & $\begin{array}{l}75(15 \\
\text { definite } \\
\text { MI; } 23 \\
\text { probable } \\
\text { MI; 10 } \\
\text { definite } \\
\text { TTH; 3 } \\
\text { probable } \\
\text { TTH; 24 } \\
\text { U) }\end{array}$ & $\begin{array}{l}97(22 \\
\text { definit } \\
\text { e MI; } \\
26 \\
\text { probab } \\
\text { le MI; } \\
14 \\
\text { definit } \\
\text { e } \\
\text { TTH; } \\
13 \\
\text { probab } \\
\text { le } \\
\text { TTH; } \\
22 \mathrm{U})\end{array}$ & NA & NA & NA & NA \\
\hline
\end{tabular}
highlighted in grey. ${ }^{a}$ associated with focal onset, most often temporal lobe, ${ }^{b}$ discrepancy in the original study, ${ }^{\mathrm{c}}$ Sex of participants not reported. ${ }^{\text {d. }}$ of which, 6 with aura. $\mathrm{ICHD}=$ International Classification of Headache Disorders. TTH=tension type headache, $\mathrm{U}=$ unclassified, TLE=temporal lobe epilepsy, FLE=frontal lobe epilepsy, OLE=occipital lobe epilepsy; MI, migraine. 
Table 2 | Features of migraine aura and occipital seizures

\begin{tabular}{|l|l|l|}
\hline Feature & Migraine & Occipital lobe seizure \\
\hline Main symptoms & Foggy or blurred vision & Visual hallucinations \\
& Zigzag or jagged lines & Visual illusions \\
& Scotoma & Blindness \\
& Phosphenes & Palinopsia \\
& Flickering light & Sensory hallucinations of ocular \\
& & movement \\
& & Ocular pain \\
& & Nystagmus, eyelid closure and/or \\
& fluttering \\
\hline Duration & Centrifugal or centripetal & No centrifugal or centripetal \\
\hline Progression & progression of visual & progression of visual symptoms \\
\hline Accompanying symptoms (e.g. & Common & \\
\hline
\end{tabular}


Figure 1 | A selection of key publications on headache in epilepsy from before 2015.

This timeline shows milestone publications in the field of headache in epilepsy. We selected publications that were particularly notable, for example, the first publication to report a specific finding, or a publication that had a large influence on subsequent research. The first reports of an overlap between epilepsy and headache were published at the end of the $19^{\text {th }}$ century. From the 1960 's onward, epilepsy was increasingly seen as a systemic disorder with many comorbidities. Technical advances in the 1980's spurred on research in this area, including studies that used animal models, in vitro approaches and depth electrodes in patients. From the early 2000's, there was an increased interest in the molecular mechanisms of anti-seizure medication and their effect on associated conditions such as migraine, and in the molecular genetics of epilepsy and migraine.

\section{Figure $2 \mid$ A timeline showing the different types of peri-ictal headaches.}

The timing of pre-ictal, ictal and post-ictal headaches is shown in relation to the seizure. Pre-ictal headaches occur $<24$ hours before a seizure and last until seizure onset. Ictal headaches develop simultaneously with the seizure. Post-ictal headaches occur $<3$ hours after the end of the seizure event and remit spontaneously $<72$ hours after seizure termination. Specific types of seizure-related headaches are also illustrated, including migraine as seizure trigger, hemicrania epileptica and headache as seizure aura.

Figure 3 | Putative pathophysiological mechanisms linking seizures and headache. a | Hyperexcitability in epilepsy often involves impaired GABAergic transmission, facilitating hypersynchronous seizure bursts. In migraine, hyperexcitability seems to be largely the result of enhanced glutamatergic transmission, which could facilitate pain pathway activation via inflammatory changes and calcitonin gene-related peptide (CGRP) release in the absence or presence of CSD. In migraine, GABAergic transmission seems to be unaltered or could be dynamically enhanced, as indicated by the results of preclinical studies on the effects of mutations associated with familial hemiplegic migraine (FHM) type 3. Strongly enhanced glutamatergic transmission in migraine resulting from pathogenic mutations, as is known to occur in FHM type 1, will increase the likelihood of co-morbid epilepsy. b | Cortical spreading depolarization (CSD) is likely to be the neurophysiological mechanism underlying 
migraine aura. CSD could also trigger migraine headache originating in the trigeminovascular system. CSD consists of a slowly propagating wave of network depolarization that is presumably caused by cortical hyperexcitability. CSD-associated increases in the concentration of potentially noxious molecules, including $\mathrm{K}^{+}$and $\mathrm{H}^{+}$(i.e. low $\mathrm{pH}$ ), in the extracellular space could reach pial, arachnoid, and dural surfaces and activate perivascular sensory afferents from trigeminal ganglion (TG) neurons. Inflammatory changes, involving neuronal release of high mobility group protein 1 (HMBG1) following CSD-induced pannexin channel opening, provide a mechanistic link between CSD and pain pathway activation. Signals from activated meningeal nociceptors are relayed through TG nerve processes to the brainstem trigeminal cervical complex (TCC) and subsequently to thalamic and cortical areas (including cingulate cortex, CC) and produce sensations of pain. Adapted from Chen et al, Cephalalgia 2019 and Ferrari et al Lancet Neurology 2015.

Box 1 | ICHD-3 diagnostic criteria relevant to epilepsy

\section{Migraine aura-triggered seizure (ICHD-3 code 1.4.4.)}

A. A seizure fulfilling diagnostic criteria for one type of epileptic attack and criterion B below

B. Occurring in a patient with 1.2 Migraine with aura, and during or within one hour after an attack of migraine with aura

C. Not better accounted for by another ICHD-3 diagnosis.

While migraine-like headaches are quite frequently seen in the epileptic post-ictal period, sometimes a seizure occurs during or following a migraine attack.

This phenomenon, sometimes referred to as migralepsy, is a rare event, originally described in patients with 1.2 Migraine with aura. Evidence of an association with Migraine without aura is lacking.

\section{Ictal epileptic headache (ICHD-3 code 7.6.1)}

A. Any headache fulfilling criterion $\mathrm{C}$

B. The patient is having a partial epileptic seizure 
C. Evidence of causation demonstrated by both of the following:

1. headache has developed simultaneously with onset of the partial seizure

2. either or both of the following: a) headache is ipsilateral to the ictal discharge. b) headache significantly improves or remits immediately after the partial seizure has terminated

D. Not better accounted for by another ICHD-3 diagnosis.

\section{Hemicrania epileptica (ICHD-3 code 7.6.1.)}

(if confirmed to exist) is a very rare variant of 7.6.1 Ictal epileptic headache characterized by ipsilateral location of headache and ictal EEG paroxysms.

\section{Postictal headache (ICHD-3 code 7.6.2)}

A. Any headache fulfilling criterion $\mathrm{C}$

B. The patient has recently had a partial or generalized epileptic seizure

C. Evidence of causation demonstrated by both of the following:

1. headache has developed within three hours after the epileptic seizure has terminated

2. headache has resolved within 72 hours after the epileptic seizure has terminated

D. Not better accounted for by another ICHD-3 diagnosis.

\section{Box 2| Spreading depolarization and seizures - a missing link underlying headache in epilepsy?}

Migraine aura ${ }^{5}$ is likely to be caused by cortical spreading depolarisation, a slow-spreading $(\sim 2-6 \mathrm{~mm}$ per min) wave of neuronal and glial depolarisation followed by neuronal silencing (evident from suppression of local field potential (LFP) or EEG activity) lasting a couple of minutes ${ }^{238-240}$. Neuronal hyperexcitability predisposes to spreading depolarisation and seizures, and might be a key shared mechanism of epilepsy and migraine ${ }^{158,241}$. Changes in ion concentration can shift neurons towards moderate depolarisation leading to synchronous epileptiform firing (part a of the figure), or — if extracellular $\mathrm{K}^{+}\left(\left[\mathrm{K}^{+}\right]_{\text {out }}\right.$ ) rises above $\sim 12 \mathrm{mM}$ - towards nearcomplete depolarisation, yielding spreading depolarisation ${ }^{122,166}$ (part b of the figure shows a hypothetical seizure 
followed by spreading depolarisation). Silencing of bioelectrical activity during spreading depolarisation is caused by sustained neuronal depolarisation that exceeds the inactivation threshold for ion channels, thus preventing action potentials ${ }^{123}$. Conversely, post-ictal suppression in the absence of spreading depolarisation is associated with neuronal hyperpolarisation ${ }^{136}$. Spreading depolarisation-related suppression should not be confused with post-ictal generalised EEG suppression (PGES) ${ }^{242}$, which is an immediate (within 30 seconds) complete suppression of EEG activity following a seizure ${ }^{243,244}$. Clinically, PGES appears non-spreading ${ }^{245}$, lasts up to 338 seconds (mean 46 seconds) and is associated with motionlessness ${ }^{246}$, whereas changes in perception associated with migraine aura last $\sim 20-30$ minutes $^{123}$. Preclinical work has indicated that network suppression by spreading depolarisation prevents seizures ${ }^{111}$, suggesting that post-ictal spreading depolarisation constitutes an intrinsic seizure-termination process. The link between spreading depolarisation and headache remains unclear. In rodents, spreading depolarisation activates the trigeminovascular system at the meningeal level ${ }^{77,247}$ (Fig. 3) and might affect the brainstem via a corticotrigeminal projection ${ }^{74}$. How the trigeminovascular system is activated in humans remains unclear, and cortical spreading depolarisation could be one of many triggers ${ }^{74}$. No clear evidence exists that spreading depolarisation occurs in association with epileptic discharges in humans outside of trauma or stroke ${ }^{123,124}$. When cortical spreading depolarisation was observed in individuals with ischemic stroke, headaches were not reported ${ }^{248}$. Research in rodents indicates that the excessive network activity during seizures and associated increases in extracellular $\mathrm{K}^{+}, \mathrm{H}^{+}$and inflammatory changes might be sufficient to activate the trigeminovascular system without the need of a spreading depolarisation ${ }^{103}$.

Part A adapted from $\mathrm{REF}^{136}$. Part $\mathrm{B}$ is a stylized representation of the changes that are thought to occur during post-ictal spreading depolarization ${ }^{122,158}$.

\section{Supplementary Video 1 | Video-EEG recording of an individual with ictal epileptic headache}

